\title{
An ethnographic study of injecting drug users and men who have sex with men in selected states in Nigeria
}

Enhancing Nigeria's HIV/AIDS Response (ENR) Programme

Follow this and additional works at: https://knowledgecommons.popcouncil.org/departments_sbsr-hiv

Part of the Demography, Population, and Ecology Commons, Family, Life Course, and Society Commons, Gender and Sexuality Commons, International Public Health Commons, and the Medicine and Health Commons How does access to this work benefit you? Let us know!

\section{Recommended Citation}

Enhancing Nigeria's HIV/AIDS Response (ENR) Programme. 2012. "An ethnographic study of injecting drug users and men who have sex with men in selected states in Nigeria." Abuja: Enhancing Nigeria's HIV/ AIDS Response (ENR) Programme. 


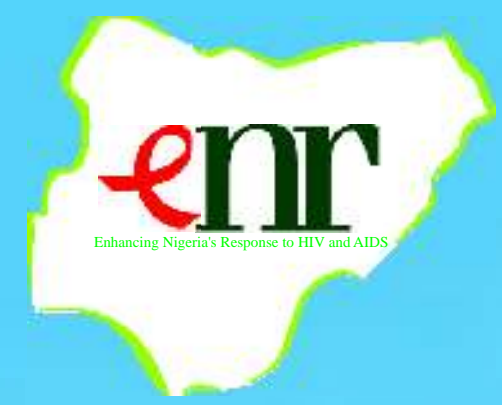

Enhancing Nigeria's Response to HIV and AIDS (ENR) Program

\section{AN EHNOGRAPHIC STUDY ON INJ ECTING DRUG USERS AND MEN WHO HAVE SEX WITH MEN IN SELECIED STATES IN NIGERIA}

DFID International
Development 


\section{AN ETHNOGRAPHIC STUDY OF \\ INJECTING DRUG USERS AND MEN WHO HAVE SEX WITH MEN \\ IN SELECTED STATES IN NIGERIA}




\section{Recommended Citation:}

Enhancing Nigeria's HIV/ AIDS Response (ENR) Programme: An Ethnographic Study of Injecting Drug Users and Men who have Sex with Men in selected States in Nigeria. 2012 ISBN: 978 - 978 - 51172-1-9 


\section{TABLE OF CONTENTS}

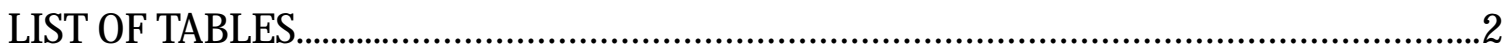

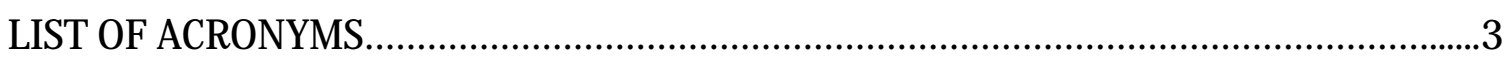

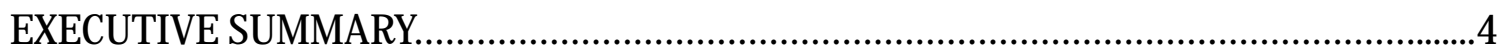

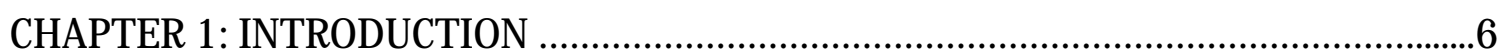

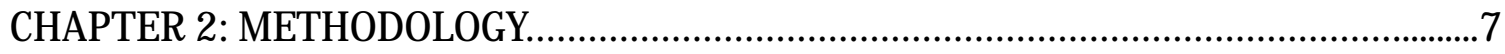

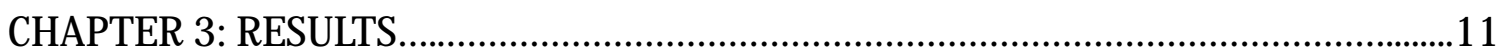

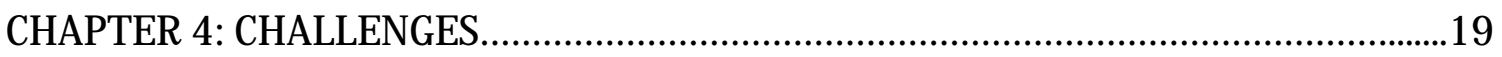

CHAPTER 5: CONCLUSIONAND RECOMMENDATION.....................................21

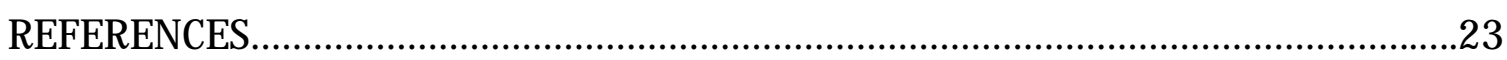

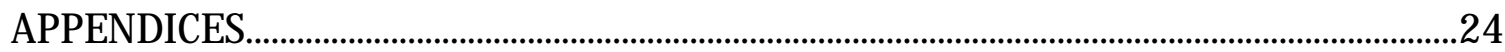

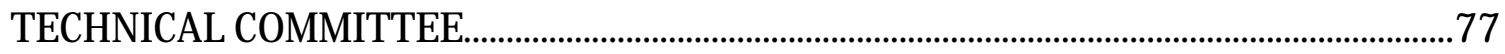




\section{LIST OF TABLES}

Table 1: Logical framework for the IBBSS ethnographic pre-assessment study....................10

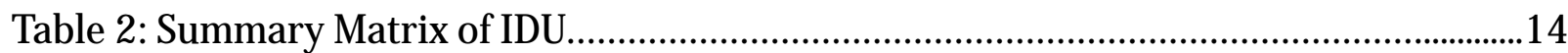

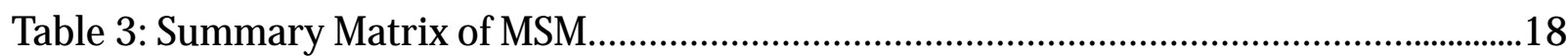




\section{LIST OF ACRONYMS}

\begin{tabular}{ll} 
DFID & Department for International Development \\
ENR & Enhancing Nigeria's Response to HIV/ AIDS \\
FGD & Focus Group Discussion \\
FGN & Federal Government of Nigeria \\
FHI & Family Health International \\
HIV & Human Immunodeficiency Virus \\
IBBSS & Integrated Biological and Behavioural Surveillance Survey \\
IDI & In-depth Interview \\
IDU & Injecting Drug User \\
IEC & Information, Education and Communication \\
KII & Key Informant Interview \\
LGBT & Lesbians, Gay, Bi-sexual and Transgender \\
MARPs & Most-at-risk Populations \\
MSM & Menwho have Sex with Men \\
NACA & National Agency for the ControlofAIDS \\
NASCP & National AIDS/ STIControl Programme \\
RAP & Rapid AssessmentProcedures \\
SAPC & StateAIDSProgramme Coordinator \\
STI & Sexually Transmitted Infection \\
USAID & United States Agency for International Development \\
WHO & World Health Organization \\
\hline
\end{tabular}




\section{EXECUTIVE SUMMARY}

The ethnographic pre-assessment study of the behavioural dynamics of men who have sex with men (MSM) and injecting drug users (IDU) was conducted in October, 2009, as an integral part of the 2010 IBBSS. The study took place in Abuja, Calabar, Ibadan, Kaduna, Kano, and Lagos, with the sites representing a zonal distribution of three states each from northern and southern Nigeria. The pre-assessment study provided rich contextual information on the logistic and scientific factors that would aid successful conduct of the 2010 IBBSS and secure buy-in for it among the different study respondents in the IBBSS. It utilized a combination of rapid assessment procedures (RAP) that were suitable to prevailing time exigencies and could foster preliminary understanding of the local contexts of risk behaviors of IDU and MSM. Its data follow on the results of the 2007 IBBSS and reinforce the status of IDUand MSMas significant risk communities in the six states in Nigeria.

The overall results show that logistical and technical aspects are important for the conduct of the 2010 IBBSS. The logistical issues include how and when to recruit respondents; confidentiality issues; decisions about venues before commencement of the survey; objective recruitment of fieldworkers; review of the incentive system for respondents and provision of adequate state-level security through effective liaison with the state security apparatus. These were among the most important issues that emerged from the preassessment study. For IDU, the sites for injecting drugs are sometimes the same as those used for smoking marijuana and abuse of other substances like alcohol. This finding indicates that injecting drug use takes place in a behavioural collage of alternating patterns of drug use, with preferences shifting with available substance, networks, opportunities and resources. For MSM, the meeting sites and venues for encounter vary to include private residences in situations where local stigma and condemnation are strong.

The technical results show that there are active IDU and MSM sub-populations in all the states, with the exception of Oyo State, where marijuana use and the identified number of IDUs were low. The IDU and MSM communities in the states cut across nationality, class, religion, ethnicity and other socio-demographic characteristics. Respondents for the study were drawn from all social groups. Respondents for the FGDs were aged 25-50 years. They included unemployed, employed, self-employed persons and several well educated respondents. Key informants for the investigation included outreach workers, pastors who ran faith based organizations that specializein 
rehabilitation work and also work with drug sellers, enforcers, and "Chairmen" as gatekeepers to the IDU community. The investigation shows that it is advisable for interviews and discussions with IDUnot to be held when IDUare intoxicated.

The IBBSS pre-assessment study exercise was successful in large part because of the commitments of partners. The major challenges included the short time frame for the task and security arrangements, which had not been concluded by the time fieldwork commenced. Much can be developed on the strength of these preliminary logistical and technical findings to support the design and implementation of the 2010 IBBSS. The 2010 IBBSS should address the limitations of the 2007, which did not ensure local ownership of the results. Adequate attention should be paid to the need for advocacy and information sharing among all stakeholders.

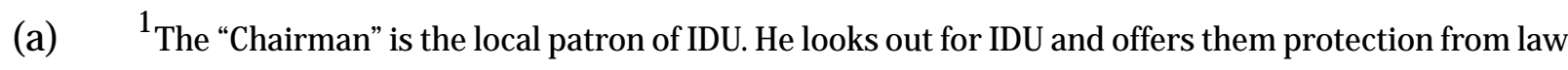
enforcement agencies. Since his livelihood depends on the drug habit of IDU, the guardian role he plays and the control he exerts over IDU is part of his occupational practices. 


\section{CHAPTER ONE}

\section{INTRODUCTION}

The Federal Ministry of Health in collaboration with National Agency for the Control of AIDS (NACA) and development partners-Family Health International (FHI/GHAIN) and Enhancing Nigeria's Response to HIV/ AIDS (ENR) planned a pre-assessment study as a prelude to the 2010 Integrated Biological and Behavioural Surveillance Survey (IBBSS). The pre-assessment study was designed to provide information that will aid the 2010 IBBSS data collection among IDUand MSM, and complement existing IBBSSprocedures.

The IBBSS is designed to assess the knowledge and beliefs of most-at-risk populations (MARPs) about HIV and STIs, determine HIV prevalence, and provide data for monitoring change over time. These MARPs include Men having sex with Men (MSM), Injecting Drug Users (IDU), female sex workers (FSW), transport workers (TW), Police and Armed Forces.

The pre-assessment study was expected to foster preliminary understanding of the local contexts in which risk behaviors of MARPs occur. This would help to relate the IBBSS survey findings on IDU and MSM HIV prevalence to their dynamic behavioral networks and milieus. Combined with empirical results from the 2010 IBBSS, the findings from the pre-assessment study will enhance understanding of the context, beliefs, knowledge and practices that influence prevalence of HIV and perceptions of HIV prevention, treatment and care among IDU and MSM. This information will complement advocacy efforts among service providers and policy makers to improve HIV-related services among IDUand MSM.

The specific objectives of the pre-assessmentstudy were:

1. To explore the knowledge and beliefs that influence population-based estimates of prevalence of HIV and behavior among IDUand MSMin the selected states in Nigeria.

2. To explore the socio- cultural factors that affect IDU and MSM risk behaviors. As well as the perception of health providers and institutions on HIV prevention, behaviours, utilization of HIV related services and willingness to participate in HIV prevention and treatment programmes

3. To document the operational factors that guide data collection processes of the IBBSS among IDUand MSMin Nigeria. 


\section{CHAPTER TWO}

\section{METHODOLOGY}

\subsection{Study area, population and design}

This study was conducted in five states and Federal Capital Territory (FCT) in Nigeria. Cross River, Lagos, and Kano were purposively selected based on previous IBBSS conducted in 2007 while Oyo, Kaduna and the FCT were selected based on anecdotal information. The study population was IDU and MSM located in large urban cities. The categories of persons interviewed for key information included officials of the ministries of health, outreach workers, members of relevant men's association, pastors who ran faith based organizations focused on rehabilitation of drug users, drug sellers, enforcers, and "Chairmen"

The study utilized qualitative methods, which include key informant interviews (KIIs), focus group discussions (FGDs), in-depth interviews (IDIs) and ethnography.

A set of instruments including an observation checklist and guides for focus group discussions (FGDs), in-depth interviews (IDIs), and key informant interviews (KIIs) was developed to obtain qualitative information from these hard-to-reach groups in the six states. These instruments were used to collect information on patterns of social networking among IDU and MSM; the existence and activities of sub-groups within the target populations; their mobility trends; terminologies used within the groups; identity issues; and, from a logistic/ scientific point of view, willingness to take a HIV test, answer questions about sensitive behaviors in the IBBSS, and recruit peers for the 2010 IBBSS.

\section{$2.2 \quad$ Recruitment}

\subsubsection{Recruitment of respondents}

2 The "Chairman" is the local patron of IDU. He looks out for IDU and offers them protection from law enforcement agencies. Since his livelihood depends on the drug habit of IDU, the guardian role he plays and the control he exerts over IDU is part of his occupational practices. The chairman sometimes functions as suppliers of drugs to IDU.Access to the study population must be negotiated with the "Chairmen." 
Recruitment of respondents for the in-depth interviews utilized the knowledge base of outreach workers and other staff of local organizations and community leaders. Male respondents were recruited by word-of-mouth through mobilizers who were members of the community.

\subsubsection{Recruitment of field workers}

The selection of field workers was based on a set of criteria as contained in the guidelines developed for this study. These criteria stipulated that a field worker should:

a. Have experience conducting qualitative field research and taking field notes.

b. Have previous survey experienceand be at least 20 years old.

c. Have experience working with MSM/ IDUin study communities.

d. Have experience conducting systematic observation.

e. Have experience moderating and recording interviews and discussions.

f. Have experience preparing transcripts/ reports from written/ audio sources.

g. Be resident in the state where theinterviews and FGD will be held.

h. Be fluent in the local language and have good speaking/writing skills in English.

\subsection{Training offield workers}

The training lasted for two days. It covered diversity and sexual orientation training, scientific data collection, transcription, interpretation and reporting techniques. It also addressed the benefits of using respondent-driven sampling (RDS) to reach IDU and MSM respondentsin the IBBSS

\subsection{Data collection}

Structured FGDs, IDIs and KIIs were conducted with each target group. Each session lasted approximately 1-2 hours and interviews took place in secure and appropriate venues. While English was the main language of the interview, informal translation between English and appropriate local language was done.

\subsection{Data Management and Analysis_}

FGD, IDI and KII were audio-recorded, transcribed and thematically analysed. This included initial coding to identify themes, the addition of a second coding layer to identify broader social concepts and the utilization of a third analytic layer to move from initial concept identification to explanation. Descriptive data analysis of the socio-demographic characteristic was done. 


\subsection{Ethical considerations}

The research activities were reviewed on ethical grounds by review boards in Nigeria and the USA. Respondents provided informed consent. As the research discussed here is sensitive within a Nigerian context and as the need for complete anonymity is paramount, no identifying markers whatsoever are provided within this qualitative analysis.

Respondents were provided with refreshments and incentives to cover costs associated with attendingtheinterviews. 


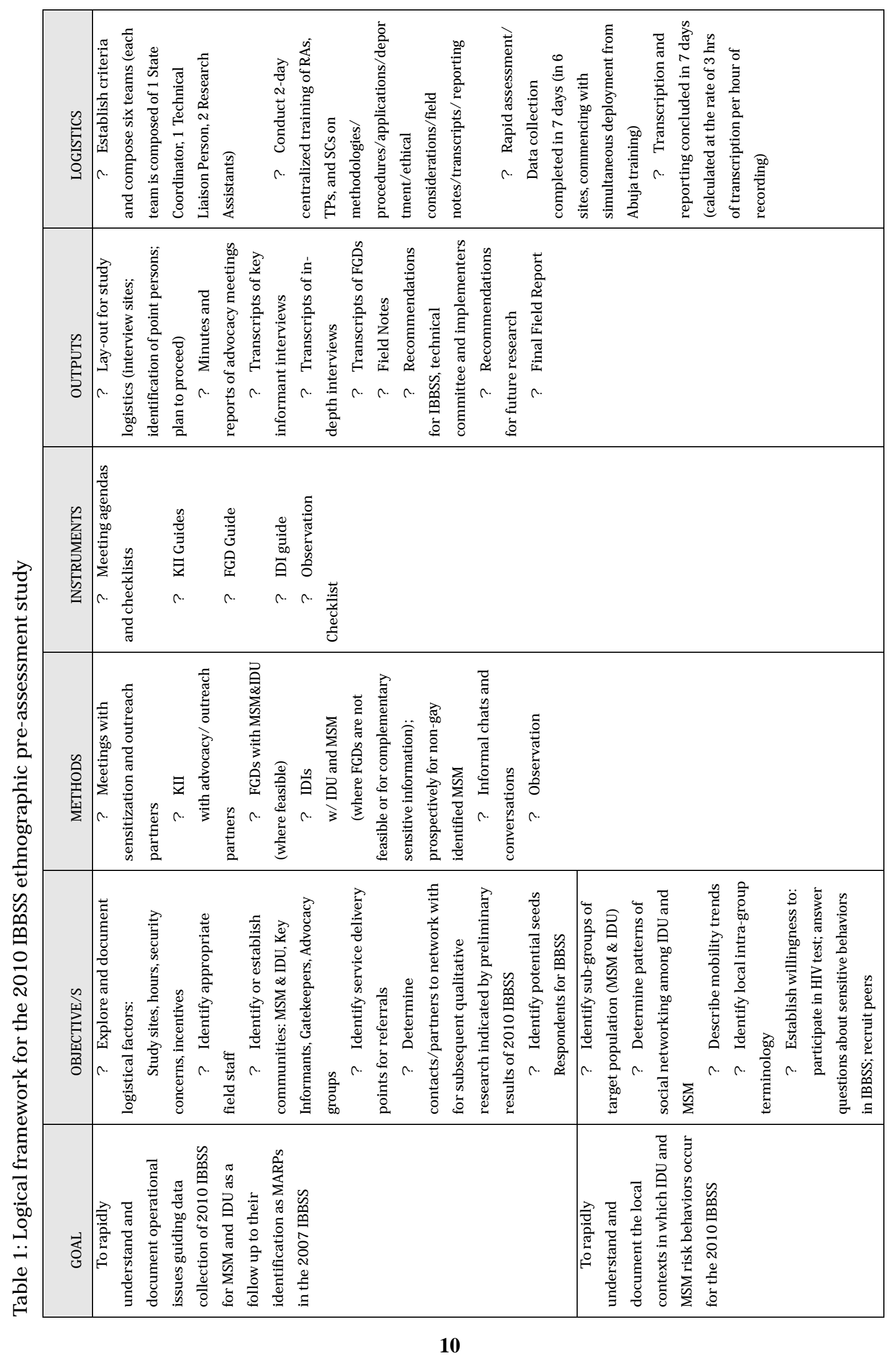




\section{CHAPTER THREE:}

\section{RESULTS}

\subsection{InjectingDrug Users}

\subsubsection{Introduction}

The IDU component of the pre-assessment study was carried out in six locations comprising 5 states (Cross River, Kaduna, Kano, Lagos and Oyo) and the Federal Capital Territory. The pre-assessment study revealed that, among drug using communities, the use of multiple sites is necessary for obtaining rich and diverse data and $t$ steps should be taken to ensure that IDU are comfortable with sites near their communities. In line with this, the morning period appeared to be most suitable for interviews and discussions because the hustle for money for drugs usually occurs in the late evenings and a FGD or IDI at that time might be viewed as an economicobstruction.

The need to establish trust and rapport with the head of the drug community in the various sites was observed, as it is sometimes up to him whether the study can be conducted among IDU or not. It is instructive to involve him in mobilizing the survey respondents. There are scientific, strategic and security reasons for this approach.

\subsubsection{Socio demographic characteristic of IDU}

IDU respondents for the FGDs ranged in age from 25-50 years, almost one in five were employed, three were self-employed and one-fifth was students. Respondents for the IDI were twenty-four in number. Many ( $42 \%$ ) were employed.

The sociodemographic characteristics of respondents were consistent across the states. Respondents were aged 25-50 years. The majority (95 percent) were less than 30 years of age. In five of the six states (the exception being Kano), about 90 percent of IDU were frequent users (shooting at least three times a day). In these five states, respondents were educated and several were university undergraduates, relative to Kano where about 80 percent of respondents were uneducated and unemployed. In Oyo State, marijuana predominated as the drug of choice and the identified number of IDU was much lower, except among higher income individuals. There were predominantly more men (99 percent) than women among the group of IDU. About 60 percent of the respondents described the presence of a large population of IDU among the Lebanese, Niger and Senegalese in some of the states. The overwhelming majority of IDU were, however, Nigerians. The results indicate that injecting drug use is a predominantly male habit.

It was recommended that interviews with IDU be brief to ensure their attention. Interviews and discussions were scheduled to avoid periods of the day when respondents often injected drugs. 


\subsubsection{Diversity and identification of IDUsub-populations}

The population of IDUs is high across five of the six locations where the pre-assessment study was carried out. Densities were highest in Kano, Lagos, Abuja, and Calabar, possibly in that order, owing to the population sizes of Kano and Lagos. The population of IDUwas low in Ibadan relative to the other five sites. With the exception of Lagos and Kano, where the IDU population is well dispersed, IDUs appear to be concentrated within the capital cities. This distribution may be linked to the urban nature of injecting drug use owing to its urban distribution channels and financial requirements of habit sustenance.

Ways of identifying people who injected drugs included the injection marks on their arms, wrists, thighs and also general behavior, unkempt appearance, irritability and not willing to stay in a position for a very long time. The preferred venues for injecting drug use include uncompleted buildings, hotels, galleries, clubs, and "joints" (places where drug can be obtained). These venue preferences reinforce the connections between injecting drug use with violent crime. Some IDUs reside in the slum. In Ibadan, it was reported that IDU lived in "high class areas because the low class generally don'tinject because they don't have privacy to inject, but those who inject use their houses or offices." This class context may account for the initial difficulty in gaining access to Ibadan-based IDU. The habit is more secretive in this city than was the case in the otherstates.

There are two main classes of IDU - wealthy and low income users. Among wealthy users are prominent individuals - politicians, businessmen and top government officials. They are not easy to locate except in special locations like clubs, galleries, and hotels. Low income users comprise street thugs and men who mainly work in the park or are involved in menial jobs (seeAppendices).

\subsubsection{Interview sites}

Most places chosen for the interview site during the pre-assessment study were adequate, except in Lagos and Calabar, where hospital venues were specifically not desirable. In such cases, there was apprehension on the part of the respondents and the Chairmen that registration, or some other form of status formalization, could be accomplished by the hospital or other formal authorities such as the National Drug Law Enforcement Agency (NDLEA).

In Lagos, the population of IDU is dispersed throughout the state and city and the traffic situation can make the timing of FGDs a challenge.

The sites for injecting drugs are often the same as those used for smoking marijuana and 
abuse of other substances like alcohol. This finding indicates that injecting drug use takes place, not exclusively, but in combination with other patterns of drug use, with preferences shifting depending on what type of drug is available. In 'Oju-Ina' in Lagos, a place known clearly as a drug user's den, it is most populated by lower class users and is suspected to accommodate a variety of violent criminals. Typically, IDU do not move far from where they get the drugs.

\subsubsection{Drugsupply}

There are multiple sources of drugs in the six states and the most prominent are the dealers. In Lagos and Kano, most IDU work during the day to support the habit. This could explain the dense concentration of IDUin the metropolis.

\subsubsection{IDUnetworks}

Wealthy and low income IDUs do not necessarily mix together. Wealthy IDU seem better organized as a group than street IDU. They meet more regularly and organize more group activities, such as social events, drug parties and support groups. In Lagos and Kano, IDU are dispersed, but in the other cities, they are concentrated in the metropolis. In Abuja, they are found in Durumi, Wuse, Mabuchi, Zone 3 Neighbourhood Area, Apo, Nyanya, and most satellite towns. In Calabar, they are concentrated in Nelson Mandela, Atimbo, Edem Street, Anantighaarea, Calabar Municipality, and ESE Life Street.

Network leaders were identified in all cities where the survey took place. A faith based organization (FBO) working with IDU was identified in Ibadan, Oyo State. Network leaders are adequate agents for recruiting of respondents. In general, it was easier to reach lowincome IDUthan their more affluent counterparts.

\subsubsection{Logistics and incentives}

Most IDUs patronize their dealers in the mornings and late in the evenings. In Lagos, IDU in the high socio-economic status usually spend the night of the last Friday in the month partying. Low-income IDU are more likely to participate in a study than their richer counterparts.

There were demands for money by gatekeepers, whose roles can be formidable. A minimum incentive required by respondents is NGN 2,000 and NGN 50,000 for network leaders. Wealthy IDU might not be persuaded by cash incentives to participate in a study for fear of exposure. 
Table 2: Summary Matrix for IDU

\begin{tabular}{|c|c|c|}
\hline & Notes/ Observations & RDS Implications \\
\hline $\begin{array}{l}\text { Geographic } \\
\text { spread for } \\
\text { recruitment }\end{array}$ & $\begin{array}{l}\text { Typically, IDU do not move } \\
\text { far from where they get the } \\
\text { drugs. }\end{array}$ & Select a study site near the drug buying area. \\
\hline $\begin{array}{l}\text { How well } \\
\text { networked } \\
\text { are these sub- } \\
\text { populations? }\end{array}$ & $\begin{array}{l}\text { IDU cut across the entire } \\
\text { spectrum of class, religious, } \\
\text { ethnic and other socio- } \\
\text { demographic } \\
\text { characteristics. . Among } \\
\text { wealthy users are } \\
\text { prominent individuals - } \\
\text { politicians, businessmen } \\
\text { and top government } \\
\text { officials. They are not easily } \\
\text { seen around except in } \\
\text { special locations like clubs, } \\
\text { galleries, and hotels. }\end{array}$ & $\begin{array}{l}\text { 1. Diversify seeds by religion, ethnicity, class, } \\
\text { and education. } \\
\text { 2. Again, make sure we include seeds from clubs, } \\
\text { gallerias and hotels. } \\
\text { 3. We need to be aware that we will not likely be } \\
\text { able to recruit these wealthier IDU since that's } \\
\text { the nature of RDS. It will most likely attract } \\
\text { those who need the money, unfortunately. } \\
\text { However, we must keep this in mind when } \\
\text { drawing conclusions and making } \\
\text { recommendations. }\end{array}$ \\
\hline Logistics & $\begin{array}{l}\text { The preferred venues for } \\
\text { injecting drug use include } \\
\text { uncompleted buildings, } \\
\text { hotels, galleries, clubs, and } \\
\text { joints. }\end{array}$ & $\begin{array}{l}\text { Try to set up study site for IDU that are in close } \\
\text { proximity to a cluster of these sites. Select some } \\
\text { seeds from these different sites as they will } \\
\text { likely link us into different networks. }\end{array}$ \\
\hline Miscellaneous & $\begin{array}{l}\text { There is a need to establish } \\
\text { trust and rapport with the } \\
\text { head of the drug community } \\
\text { in the various sites (known } \\
\text { as the 'Chairman'). It is } \\
\text { sometimes up to him } \\
\text { whether the study can } \\
\text { move forward among IDU } \\
\text { or not. } \\
\text { Attention span of IDU is } \\
\text { brief, particularly just } \\
\text { before or soon after they } \\
\text { get their fix (drugs) They } \\
\text { are hustling drugs in the } \\
\text { evening. Morning period } \\
\text { appears to be most suitable } \\
\text { for interviews }\end{array}$ & $\begin{array}{l}\text { If these Chairmen are injectors themselves and } \\
\text { meet the eligibility criteria, we should include } \\
\text { them as seeds. Regardless of whether Chairmen } \\
\text { inject, we need to inform them of the IBBSS and } \\
\text { get their support and ask them to spread the } \\
\text { word about the study. They should be } \\
\text { approached about whether they can recommend } \\
\text { any good seed respondents (i.e., those who meet } \\
\text { the eligibility criteria and are well-networked } \\
\text { and respected in the IDU community). } \\
\text { 1. Ensure sufficient \# of staff at the IDU data } \\
\text { collection sites. } \\
\text { 2. Develop efficient flow of study visit to ensure } \\
\text { speedy study visit. } \\
\text { 3. This may require having on-call interviewers. } \\
\text { 4. Make sure you have beverages to offer } \\
\text { respondents. } \\
\text { 5. Be prepared to postpone interviews of } \\
\text { potential IDU respondents if they are not } \\
\text { capable of completing study visit for that day. } \\
\text { Ask them to return the next day. } \\
\text { 6. Study site should be open during morning } \\
\text { hours and into the afternoon, but not into the } \\
\text { evening for security reasons. }\end{array}$ \\
\hline
\end{tabular}




\subsection{Men who have sex with men}

\subsubsection{Introduction}

Similar to the IDU component of the pre-assessment study, the MSM component was also carried out in six locations comprising 5 states (Cross River, Kaduna, Kano, Lagos and Oyo) and the Federal Capital Territory. The need to establish trust and rapport with spokespersons of social networks of MSM within the states is a vital component of a successful recruitment of MSM for any survey.

\subsubsection{Socio demographic characteristic of MSM}

The ages of the fifty-three MSM recruited for the FGDs ranged from 25-50 years. One-fifth were in gainful employment, , many (23\%) were studentsand the rest were unemployed . The socio-demographic characteristics of MSM recruited for the IDIs were similar to those recruited for the FGDs. Across states, , the age range and sociodemographic characteristics of respondents were also similar. Key informant interviews were held with officials of the ministries of health, outreach workers and members of relevant men's associations.

The results show that there were active populations of MSMin all the states studied. In Lagos, interviews were held with two MSM who were in a heterosexual marriage. One of the respondents reported preference for sex with his male partners. The interviews confirmed the existence of MSM, who had regular sexual relationships with their married or female partners, as an important bridge community for the transmission of HIV. The community of MSM in the states cut across the entire spectrum of class, religious, ethnic and other sociodemographic characteristics.

\subsubsection{Diversity and identification of MSMsub-populations}

There were many hotspots where MSMreported going to socialize in most of the cities (like clubs, bars) and in different neighborhoods however in Calabar, MSM have no specific 'hot spots' and interviews could be arranged anywhere through a non-governmental organization (NGO) called Male Attitude Network (MAN). The community is highly mobile in and out of the State. In Lagos, the dispersion of groups and intra-city traffic logjams might make access to the MSM community challenging for interviewers as MSM may have to be interviewed far apart. The need for multiple groups of interviewers and adequate means of mobility is crucial to IBBSS success. The size of the population of MSM in Lagos, Kano and Abuja seemed to be higher than in other states. In all states the MSM population was concentrated in the city centres. 


\subsubsection{Characteristics of MSM}

MSM are found in every segment of the population and like their IDU counterparts in this study, may be grouped into wealthy and low income MSM. Some MSM are students, rights activists, street boys and park boys. Older MSMare easier to interact with as they appear to have resolved outstanding identity questions. They also represent every income and professional groups.

\subsubsection{MSMnetworks}

High-income and low-income MSM communities function independently of each other. Wealthy MSM coordinate their network without reference to the low-income MSMnetworks although it is clear that sexual partnerships develop across class lines such as on occasions when travel or mobility leads to the absence of a regular partner. Both networks (i.e. high and low income sexual networks) have leaders who could help recruit MSM for the survey in all states except Oyo state where they move in cliques which are dispersed throughout the city. The MSM community in Cross River State appears to be even more elusive than in the other states owing to heightened stigma, discrimination and homophobic attitudes of Government officials in the state.

\subsubsection{Hot spots}

MSM are found in club houses, galleries, and hotels. Other places are joints, night clubs, fast foods outlets, viewing centers, cinemas and football stadia. Specific places where they are found in Kano include Badawa, Hotoro and Sabon Gari,Abedi Street and Mararaba. There are street based and brothel based MSM and they can be located in Ibedi Road, Kofar Mata and other areas with regular and dense concentration of potential male partners. They can also be found in Fegge Guest House, Hotoro Dan Marke, Sabon Gari, Zango, Dawakin Dakata, and Rimi Kebe. In Calabar, meeting places include private homes, which are well known to members of the MSMcommunity.

\subsubsection{Choice of sites}

The pre-assessment study showed a preference among MSM for certain venues that could be used for the interviews and discussions. For example, Lagos respondents were averse to the use of the facilities of the Lagos university Teaching Hospital because, as one discussant put it, 'it involves a form of "double stigmatization" - first because he had been identified as MSM and second, with added insinuation that he might be HIV-positive. The results in this regard suggest a need for follow up advocacy among this community, to minimize fear of infection that was so pronounced in some of the interviews and institute a testing and referral system for ARV and other follow up services. The facilities of hotels and NGOs were preferred venues 
for interviews byMSM. The choice of sites for the survey should be viewed in relation to areas of MSM concentration and the hotspots identified above. In Calabar, Mirage Hotel would be a suitable site for theinterviews and discussions during the 2010 IBBSS.

\subsubsection{Logistics and incentives}

There is a high willingness to participate in the study by MSM, but they cautioned on the need for confidentiality, safety and incentives. Weekends (particularly between $4 \mathrm{pm}$ and $12 \mathrm{am}$ on Saturdays) are the most suitable days for interacting with this group. The high profile groups may be difficult to access, possibly because they hold important positions in the society and might not want knowledge about their sexuality to become public. In Lagos, findings show that they could be located at the Silverbird Gallery on the last Friday of each month, at night, and at the National Theatre on Sundays. The best incentives for participation in the study that were mentioned included cash, condoms, lubricants, and education materials on HIV/ AIDS. 
Table 3: Summary Matrix for MSM

\begin{tabular}{|c|c|c|}
\hline & Notes/ Observations & RDS Implications \\
\hline $\begin{array}{l}\text { Geographic } \\
\text { spread for } \\
\text { recruitment }\end{array}$ & $\begin{array}{l}\text { There are many hotspots where } \\
\text { MSM go out to socialize in most } \\
\text { of the cities (like clubs, bars) } \\
\text { and in different neighborhoods. }\end{array}$ & $\begin{array}{l}\text { Select a study site that is central to these } \\
\text { hotspots since we know that they are familiar } \\
\text { with this area. In the larger and more spread out } \\
\text { cities, you may need to select two sites. }\end{array}$ \\
\hline $\begin{array}{l}\text { How well } \\
\text { networked are } \\
\text { these sub- } \\
\text { populations? }\end{array}$ & $\begin{array}{l}\text { MSM cut across the entire } \\
\text { spectrum of class, religious, } \\
\text { ethnic and other socio- } \\
\text { demographic characteristics as } \\
\text { with the general population. } \\
\text { Among wealthy users are } \\
\text { prominent individuals - } \\
\text { politicians, businessmen and } \\
\text { top government officials. There } \\
\text { are also many married men } \\
\text { with kids who are also MSM, } \\
\text { however, }\end{array}$ & $\begin{array}{l}\text { 1. Diversify seeds by religion, ethnicity, class, } \\
\text { and education and age, as well as by whether } \\
\text { they identify as gay or not. Seeds should also } \\
\text { include married men who have sex with men. } \\
\text { Seeds should also include MSM sex workers. } \\
\text { 2. Again, make sure we include seeds from clubs, } \\
\text { and hotels. } \\
\text { 3. We need to be aware that we will not likely be } \\
\text { able to recruit wealthy MSM. It will most likely } \\
\text { attract those who need the money. However, we } \\
\text { must keep this in mind when drawing } \\
\text { conclusions and making recommendations. }\end{array}$ \\
\hline \multirow[t]{2}{*}{$\begin{array}{l}\text { Sites and } \\
\text { hours }\end{array}$} & $\begin{array}{l}\text { Many MSM do not want to go to } \\
\text { a place where they may be } \\
\text { exposed as gay. }\end{array}$ & $\begin{array}{l}\text { Select sites that are neutral. Do no select gay or } \\
\text { LGBT venues. }\end{array}$ \\
\hline & $\begin{array}{l}\text { There are many MSM who are } \\
\text { students, but there are also } \\
\text { many who are professionals. }\end{array}$ & $\begin{array}{l}\text { Study site should be open during day hours but } \\
\text { also during some of the evening hours after } \\
\text { work and school. At least one weekend day } \\
\text { should be included. }\end{array}$ \\
\hline $\begin{array}{l}\text { Community } \\
\text { sensitization }\end{array}$ & $\begin{array}{l}\text { Most of these cities have NGOs } \\
\text { working with MSM community. }\end{array}$ & $\begin{array}{l}\text { Engage these NGOs and inform them of the } \\
\text { survey so that they can spread it among their } \\
\text { network. Also ask them to recommend seeds for } \\
\text { the study. }\end{array}$ \\
\hline Incentives & $\begin{array}{l}\text { Many wanted condoms, } \\
\text { lubricants and Information } \\
\text { Education and Communication } \\
\text { (IEC) in addition to money. }\end{array}$ & $\begin{array}{l}\text { In addition to N1000, HIV/ STI information and } \\
\text { condoms/ lubricants need to be distributed. }\end{array}$ \\
\hline Miscellaneous & $\begin{array}{l}\text { Characteristics of study staff: In } \\
\text { some cities, the MSM } \\
\text { community may be small. In } \\
\text { such instances, they may not be } \\
\text { comfortable with study staff } \\
\text { who are well-known in the } \\
\text { community. However, in a ll } \\
\text { cities, they preferred to have a } \\
\text { male interviewer. }\end{array}$ & $\begin{array}{l}\text { We would recommend having all male staff for } \\
\text { the MSM study site. However, it may not be } \\
\text { advisable to have MSM interviewers who reside } \\
\text { in the same community because respondents } \\
\text { may not want to share information with study } \\
\text { personnel they recognize. So it might be } \\
\text { advisable to have interviewers who are not MSM } \\
\text { but are trained and sensitized to work with the } \\
\text { gay men/ MSM population. }\end{array}$ \\
\hline
\end{tabular}




\section{CHAPTER FOUR:}

\section{CHALLENGES}

A set of central limitations and challenges were identified in the ethnographic preassessment study, ranging from timing and equipment to security issues. These are listed below.

1. In general, the time provided for the field exercise was one week. Also, the time available for IDU and MSM mobilization was short and this led to delay in commencement of activities.

2. The hidden nature of the target groups and the perceived societal stigmatization makes the participation of certain members like those of higher status and older age groups difficult. It is possible that the opinion of those not studied may differ from that of those who were reached who may be systematically different in sociodemographic characteristics and other important social and cultural variables. This was more noticeable in the MSMgroups.

3. There were some logistics difficulies, at the state levels, State Aids Programme Coordinators (SAPCs) were the designated leaders of their respective teams but were often overburdened with parallel duties from their office.Though laptops were provided promptly, there were slight delays in some sites in making digital recorders available.

4. Many respondents for the KIIs and IDIs requested for more incentives, refund of transportation cost and higher payment for their time but due to the limited resources, only a specific amount was given to those that participated

5. Access to IDU was challenging as they were suspicious of researchers' intentions, motives and affiliations.

6. Male respondents were sometimes uncomfortable by the presence of female moderators in their midst.

7. Some respondents did not want their responses to be recorded. They felt that their identities could be established through voice recognition systems but this was resolved by assuring the respondents that that is not possiblein this survey.

8. Formal security arrangements were not made before the commencement of the preassessment study. The exercise therefore took place inprevailing atmosphere of risk as the National Drug Law Enforcement Agency (NDLEA), together with other sister paramilitary organizations, had routinely stepped up surveillance of drug cartels and user and supplier 
networks. The intersections of drug use with crime and violence hold important safety implications for research operatives. Safety and security of investigators were potentially threatened by two sources: externally, from bunk raids by Federal anti-drug agencies, which could catch researchers in crossfire in the midst of known users and internally, from the volatile behaviour of the research respondents. 


\section{CHAPTER FIVE}

\section{CONCLUSIONAND RECOMMENDATIONS}

\subsection{Conclusion}

The IBBSS pre-assessment study generated results and insights that are crucial to the substantive survey. This was due in large part to partner commitments that pushed the process forward in spite of limitations and challenges identified above. The findings reiterate the results of the 2007 IBBSS that there are significant IDU and MSM communities in Nigeria and that their behavioural networks and preferences place them at risk HIV infection. There is much that can be developed on the basis of these preliminary logistic and technical findings in support of the 2010 IBBSS and these pre-assessment study results can help lend contextual significance to the results of the substantive IBBSS.

\subsection{Recommendations}

In light of the findings and challenges presented in the preceding chapters of this report, the recommendations are as follows:

1. There is need for effective advocacy prior to the commencement of the study, especially in states where discriminatory attitudes are still high.

2. The timeallocation for the IDU and MSM survey for the IBBSS should be increased; in part by mobilizing IDU and MSM in advance of fieldwork, as provided for in the Standard Operating Procedures. Such mobilization is also a means of facilitating access to IDU and MSM communities by allaying their suspicions of investigators' intentions.

3. SAPCs should be more dedicated for the IBBSS exercise and whenenever they are not released from their offices, competent subordinate should be delegated to lead the teams in thefield.

4. Equipment required for the field exercise should be procured in time to enable practice and demonstrations of their use during training.

5. An upward review of transportation and other incentives for respondents' time should be undertaken in order to motivate interest with them and minimize costs of participation. Budgetary provision should be made for all categories of respondents and gate keepers whose roles is formidable. Remuneration will be required at two levels. At the first level, incentives should be paid to IDU and MSM who participate in the survey. At the 
second, remuneration should be offered to network leaders and gate keepers who help recruit them.

6. Gatekeepers should be engaged well in advance of the IBBSS, such that the disruptive demands experienced during the pre-assessment study are reduced, if not eliminated altogether.

7. In order to address the concerns expressed (female interviewing MSMs) by some MSMrespondents during discussions and interviews, the provisions of the protocol for same sex facilitation of interviews and discussions should be followed strictly in the IBBSS.

8. Since recording depends on existing levels of trust between respondents and researchers, there is need to explain ethical issues of data access and restrictions under cover of the confidentiality clause to the satisfaction of respondents. Where such recourse is not adequate to persuade the respondents, then researchers must follow the provisions of the protocol and refrain from recording theinterview or discussion.

9. State-level security should be provided by the Nigeria Police and NDLEA. These arrangements should be finalized before commencement of the IBBSS.

10. Phones and phone lines, designated cars and drivers should be available for the exclusive use of the survey to avoid use by researchers of their individual phones as this might compromise safety.

11. Venues used for interviews should be different from hotels where personnel are lodged during the survey for security reasons. Most places chosen for the interview site during the pre-assessment study will be adequate for future surveys, except in Lagos and Calabar, where hospital venues were specifically mentioned as not being desirable.

12. There is need to maintain a continuing relationship with this community, to engage it for purposes of research, advocacy and intervention purposes. Once seeds have been identified in the 2010 IBBSS, it is strategic to sustain a working relationship with them.

13. For the actual 2010 IBBSS most IDUs patronize their dealers in the mornings and late in the evenings. Field staff should be deployed at these times 


\section{References}

-Adapted Guidelines for Conducting Pre-assessment study for 2010 IBBSS. 2009.

-Field Manual and Standard Operating Procedures for the IBBSS Pre-assessment study: An Ethnographic Survey of IDU and MSMin Selected States in Nigeria. 2009.

-Babbie, Earl. 2005. The Basics of Social Research. Third edition. Belmont, CA.: Thomson Wadsworth.

-Booth, Wayne C., Gregory G. Colomb, and Joseph M. Williams. 2003. The Craft of Research. 2nd edition. Chicago: The University of Chicago Press.

-Integrated Biological and Behavioural Surveillance Survey (IBBSS). Federal Ministry of Health. 2007 


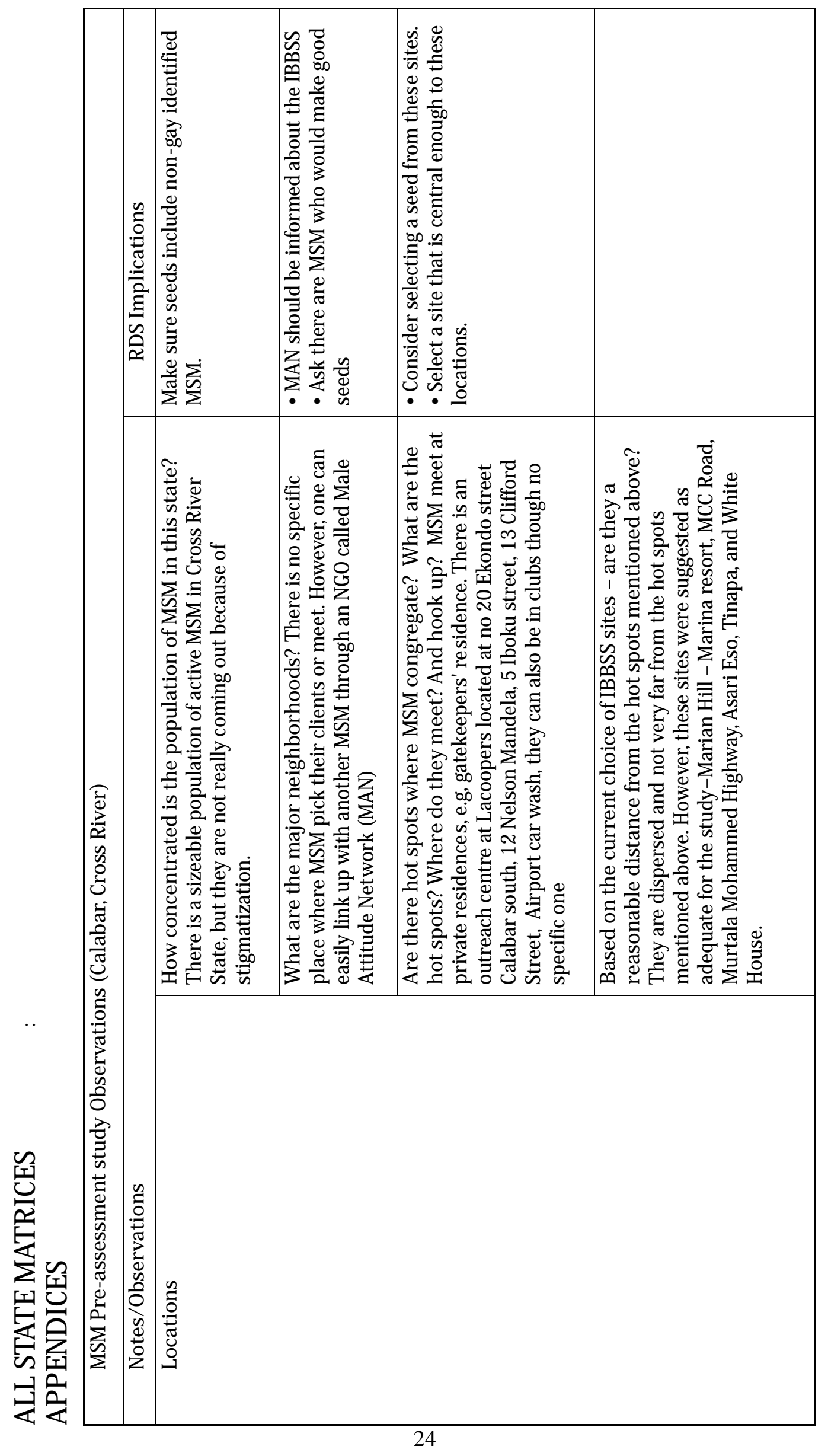




\begin{tabular}{|c|c|c|c|c|c|c|}
\hline & 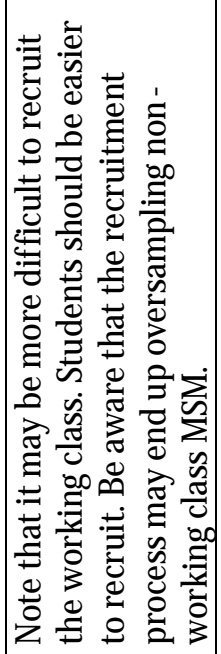 & 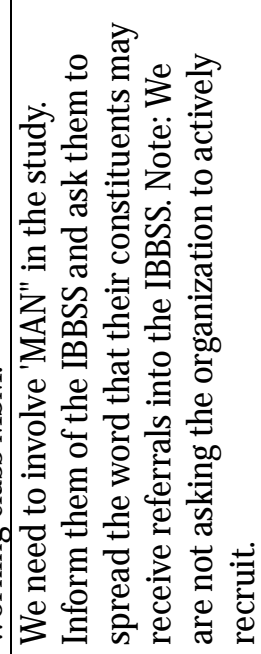 & 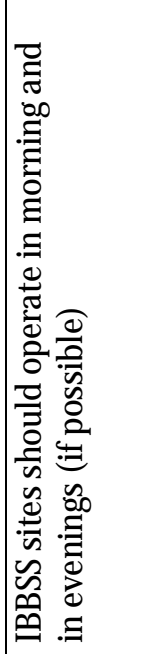 & 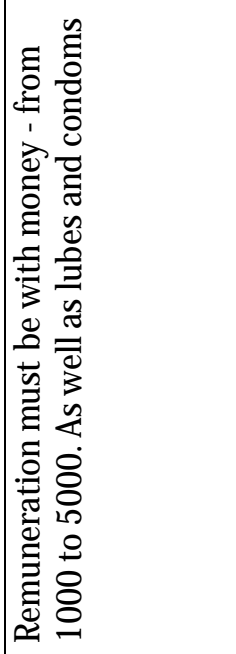 & 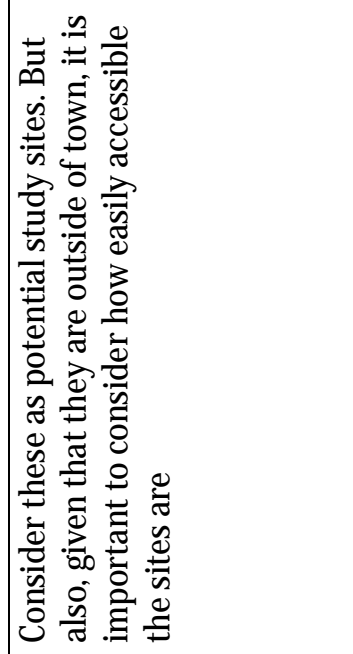 & 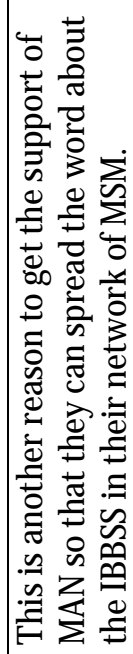 \\
\hline 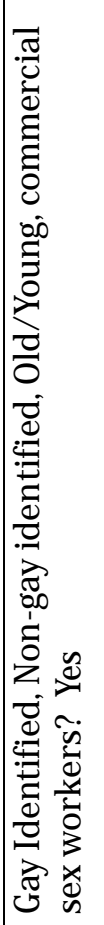 & 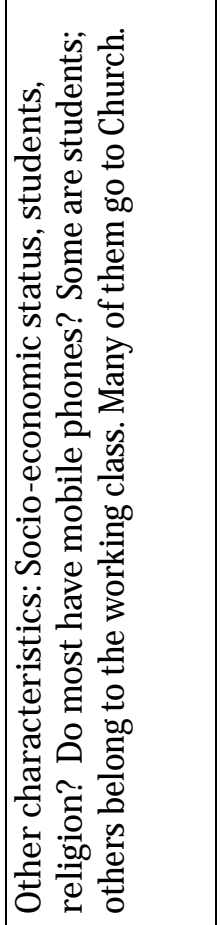 & 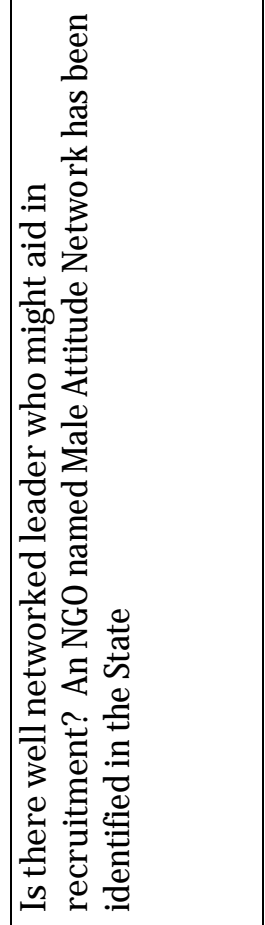 & 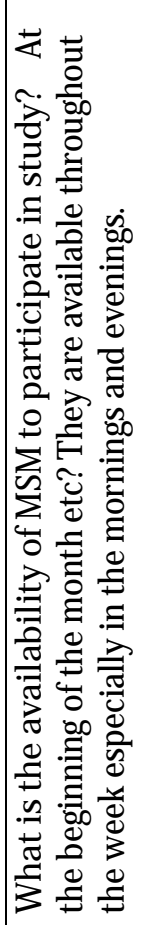 & 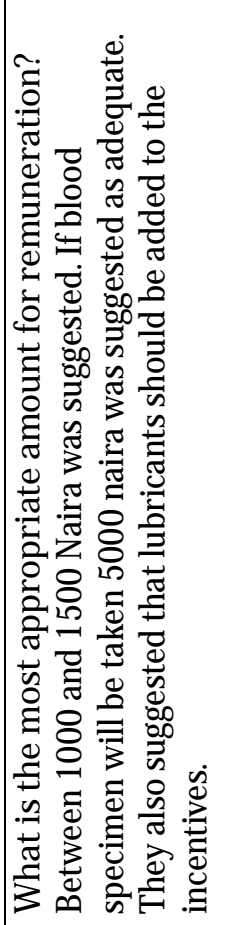 & 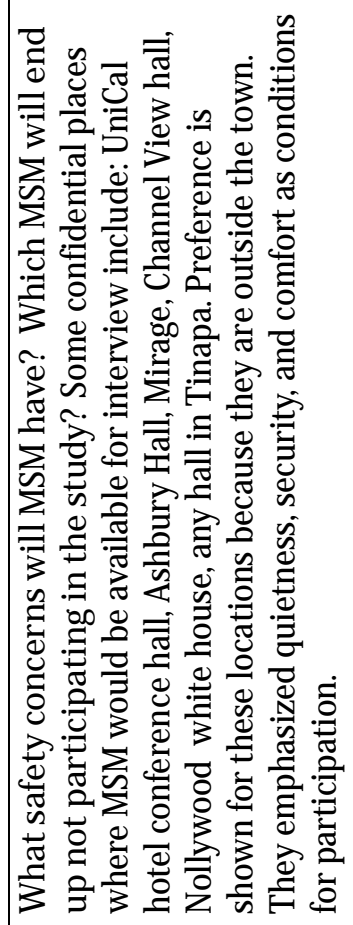 & 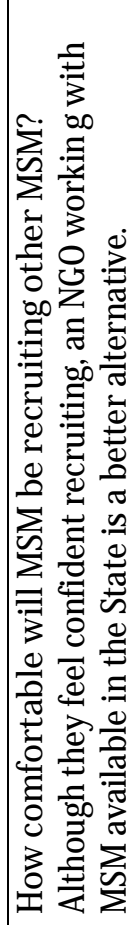 \\
\hline 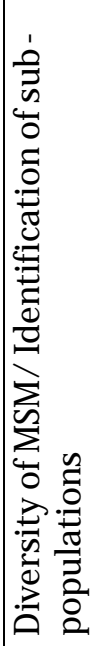 & & & 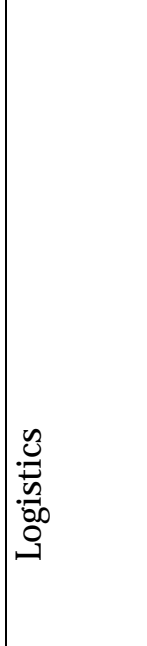 & & & \\
\hline
\end{tabular}




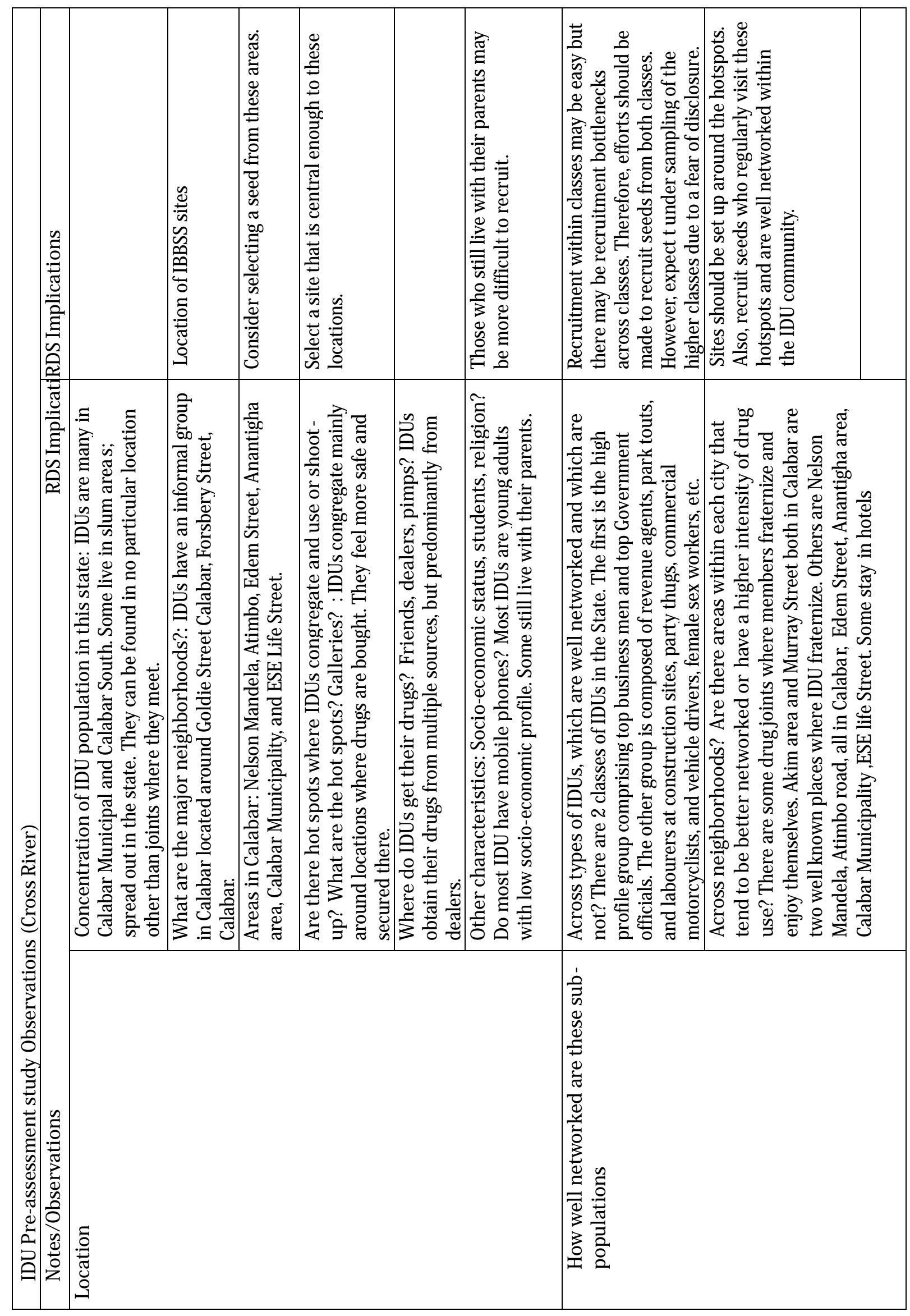




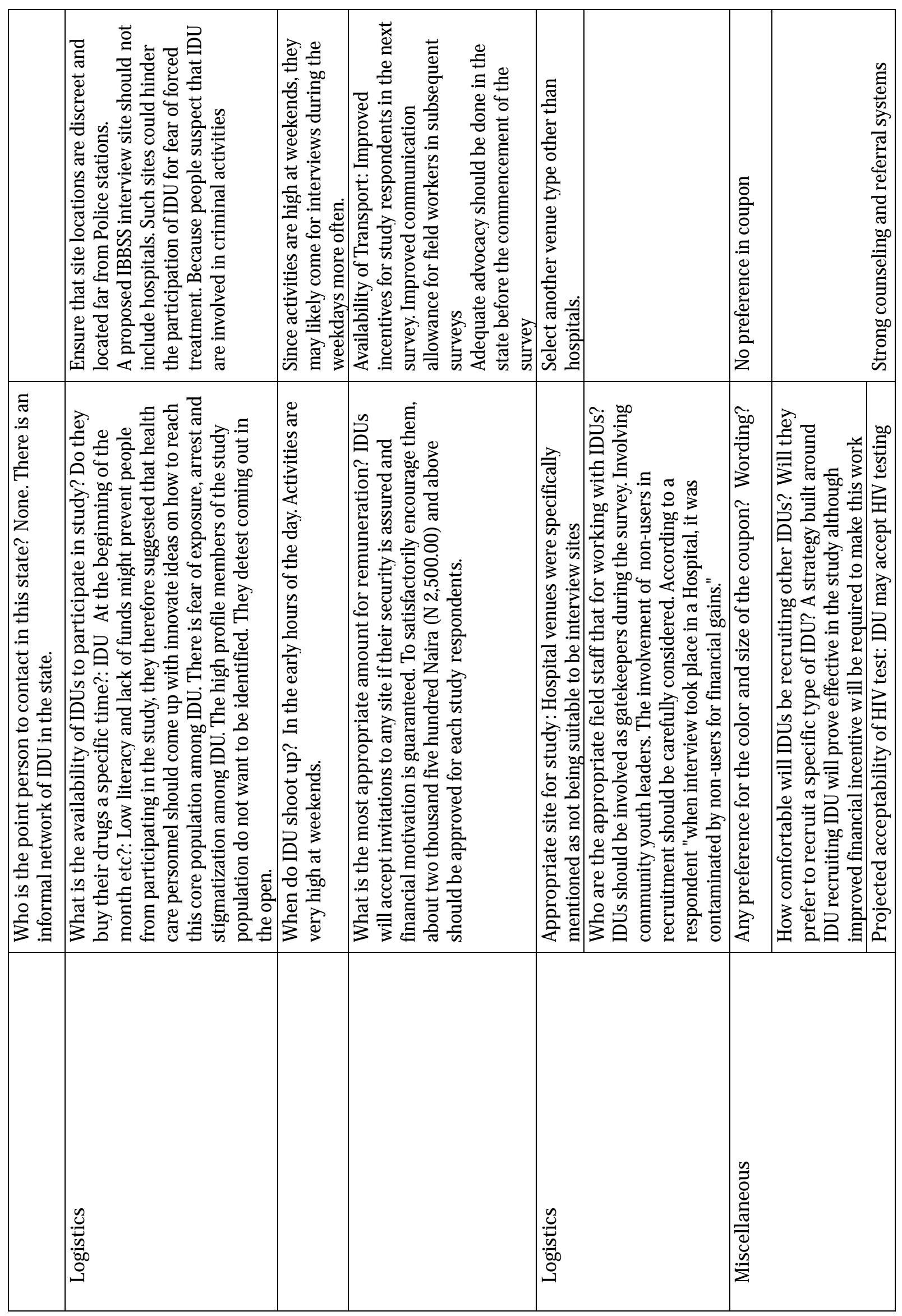




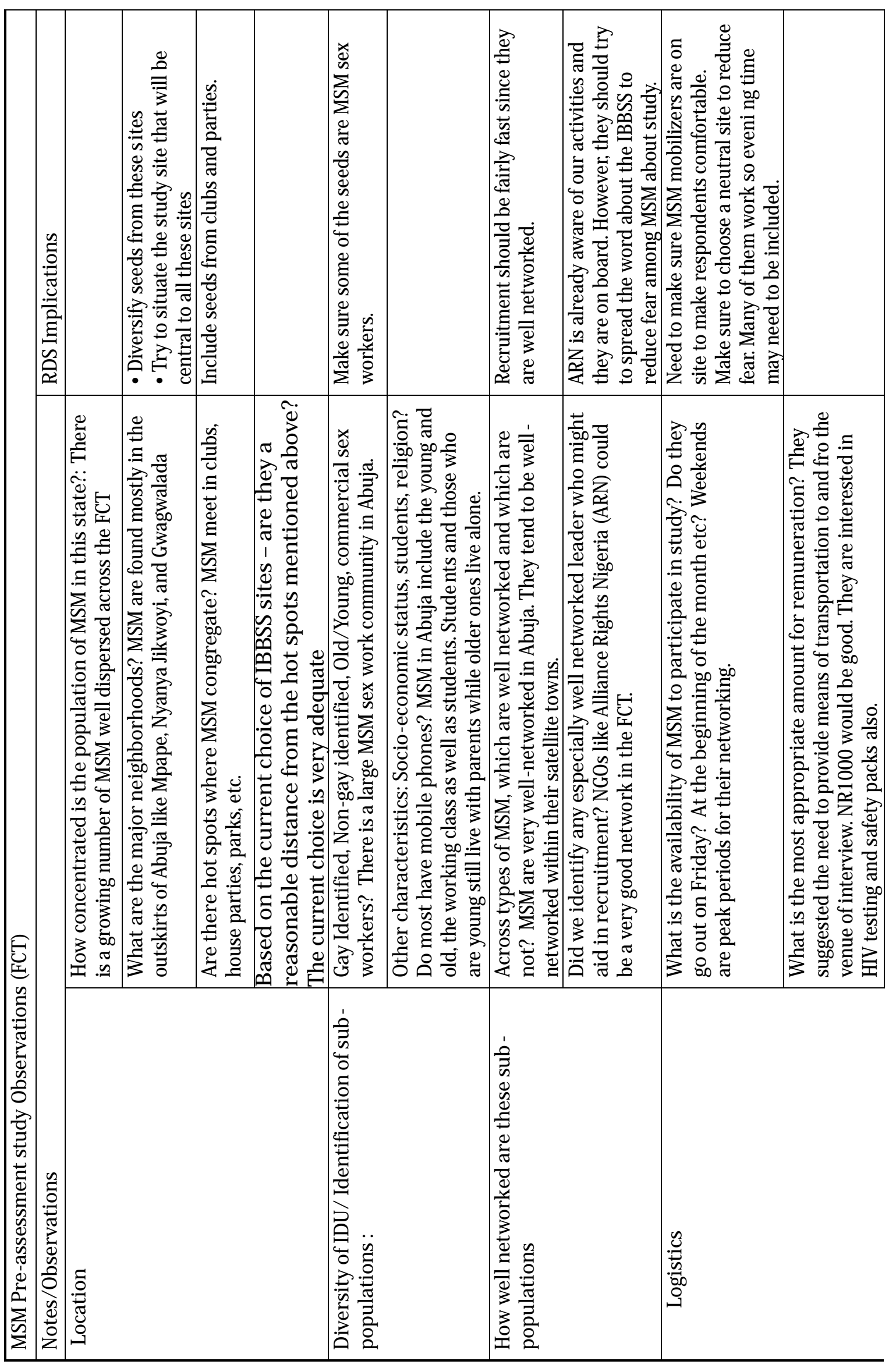




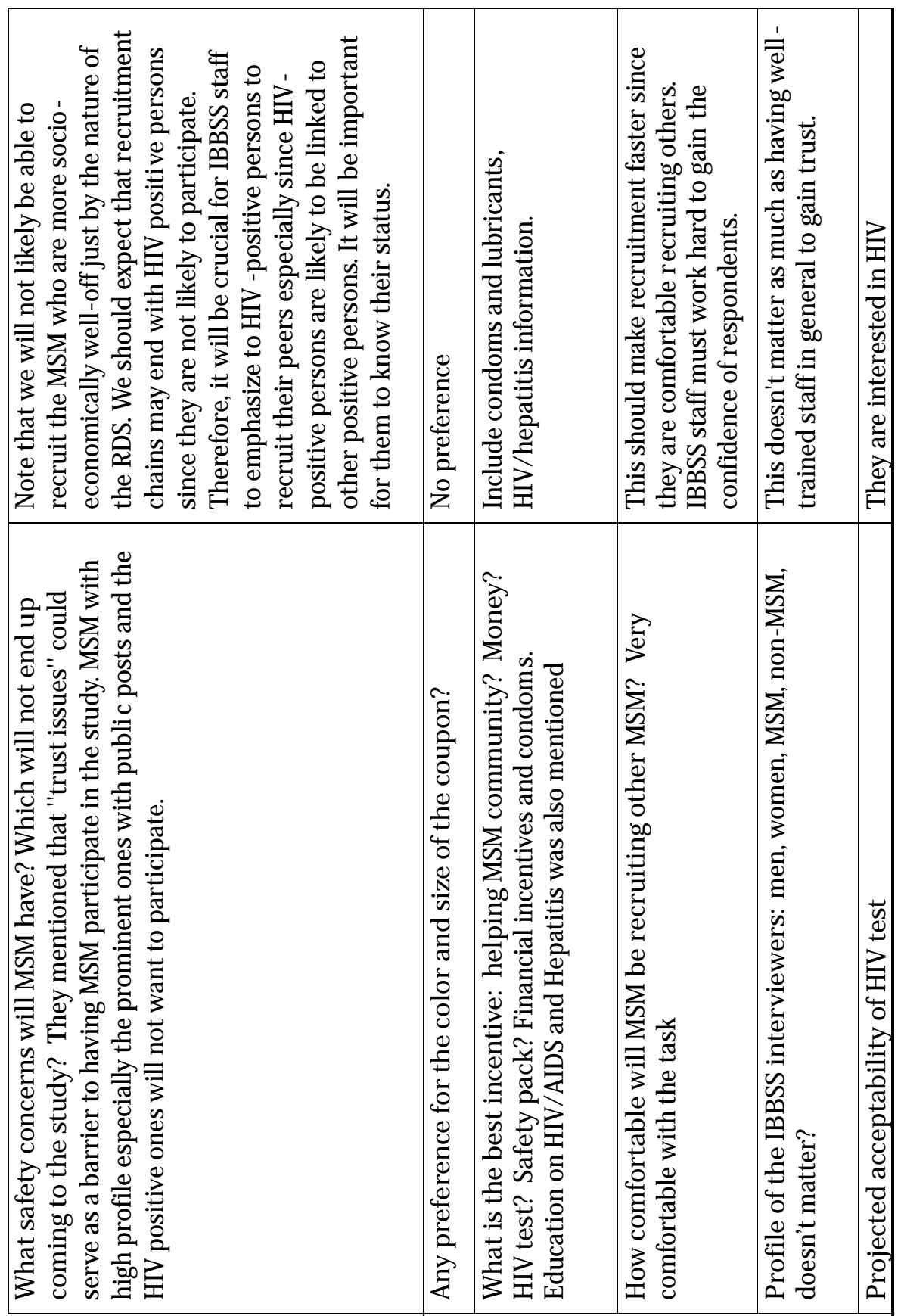




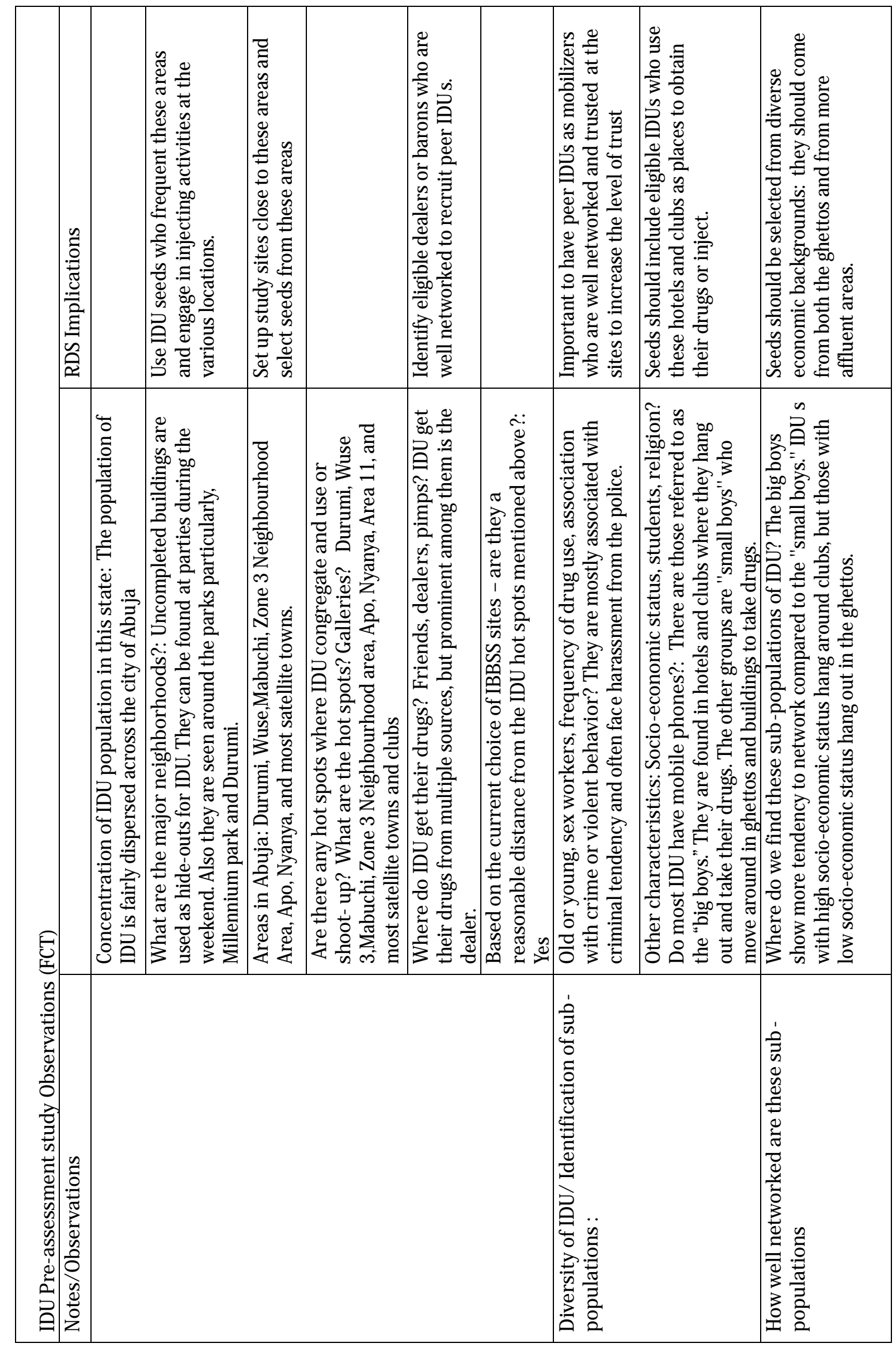




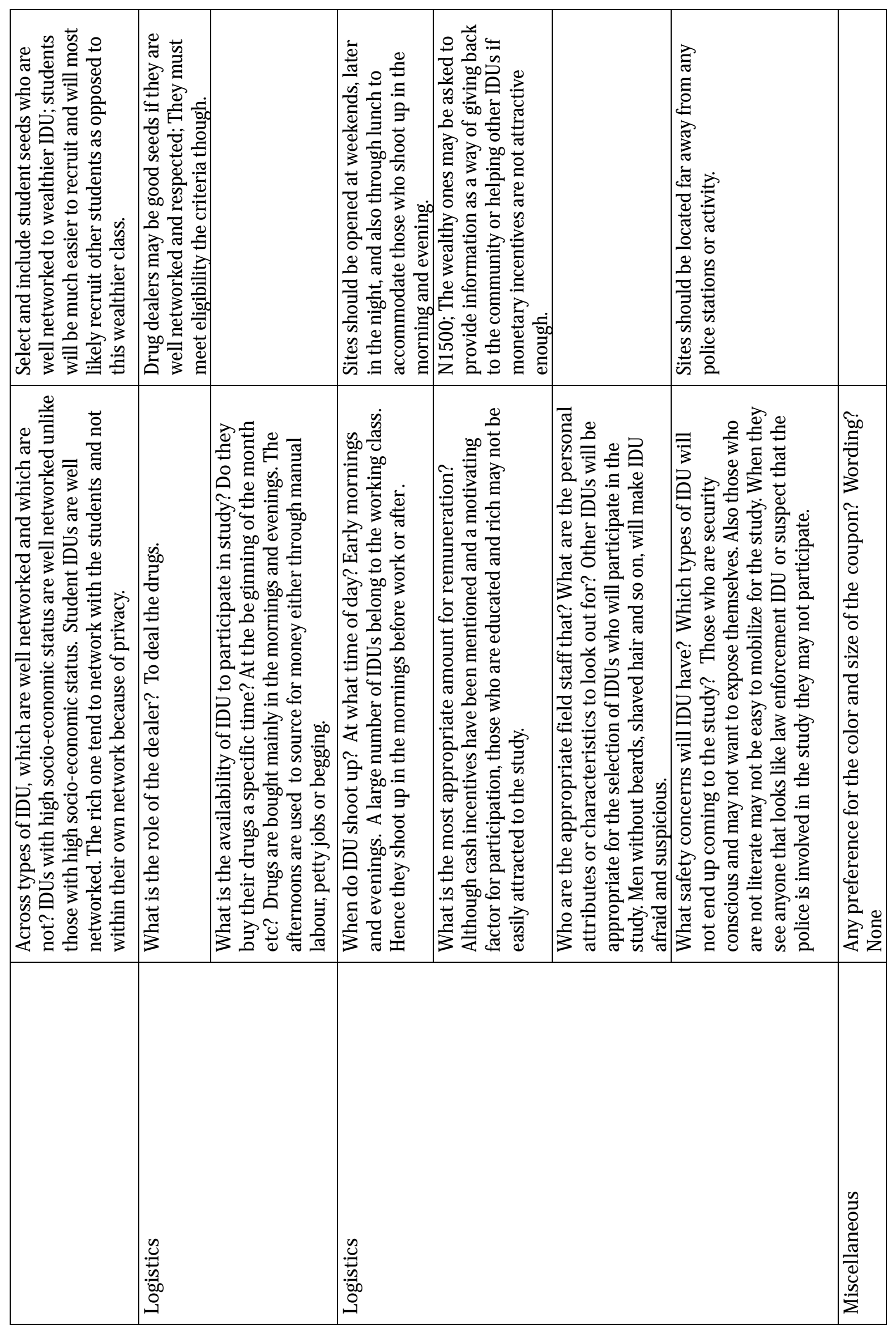




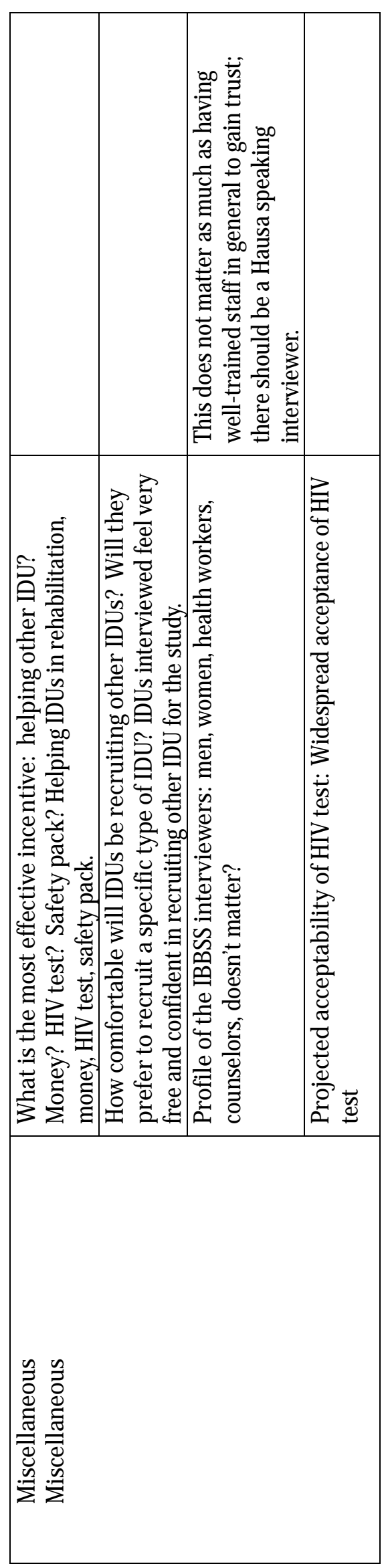




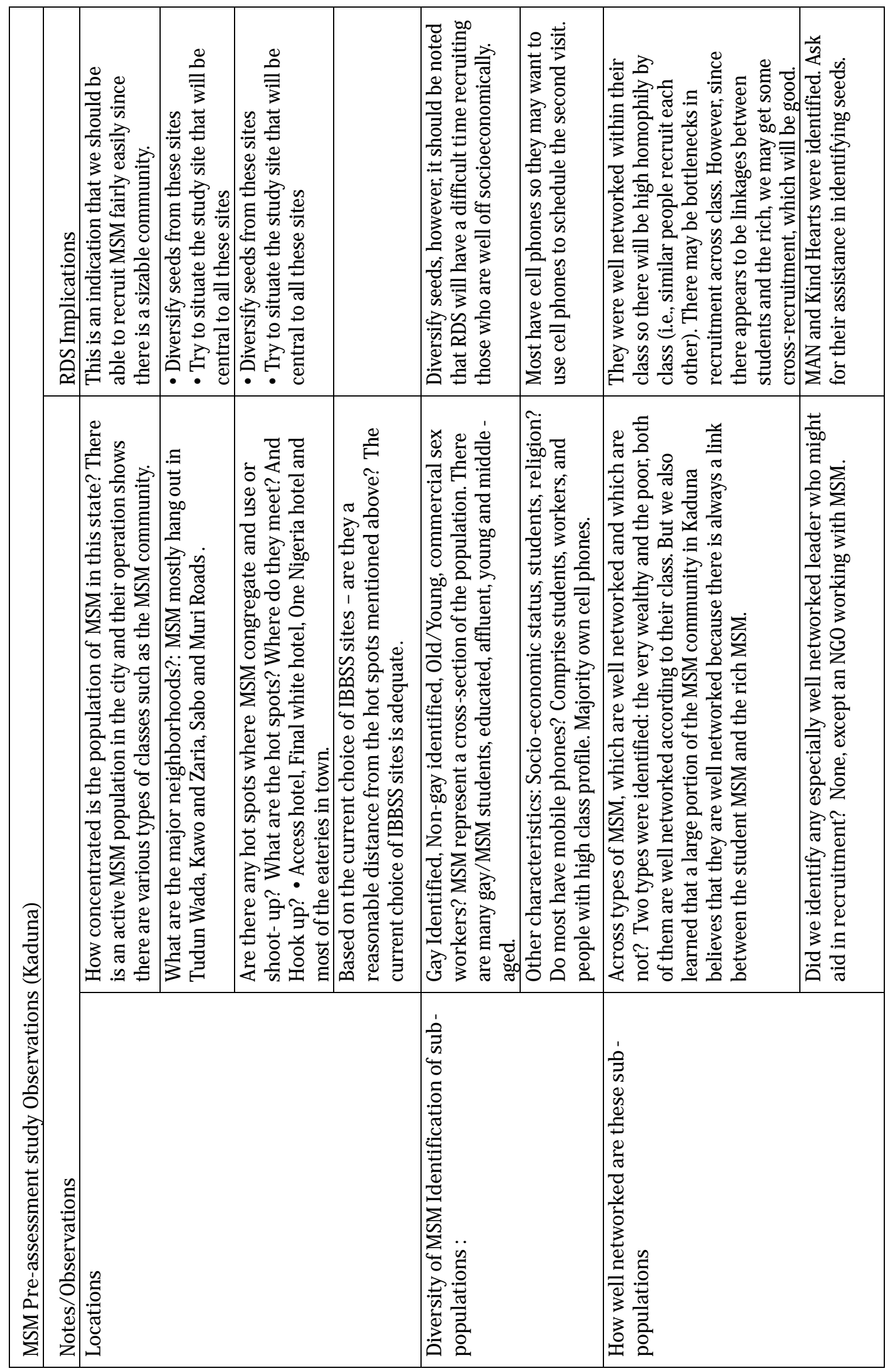




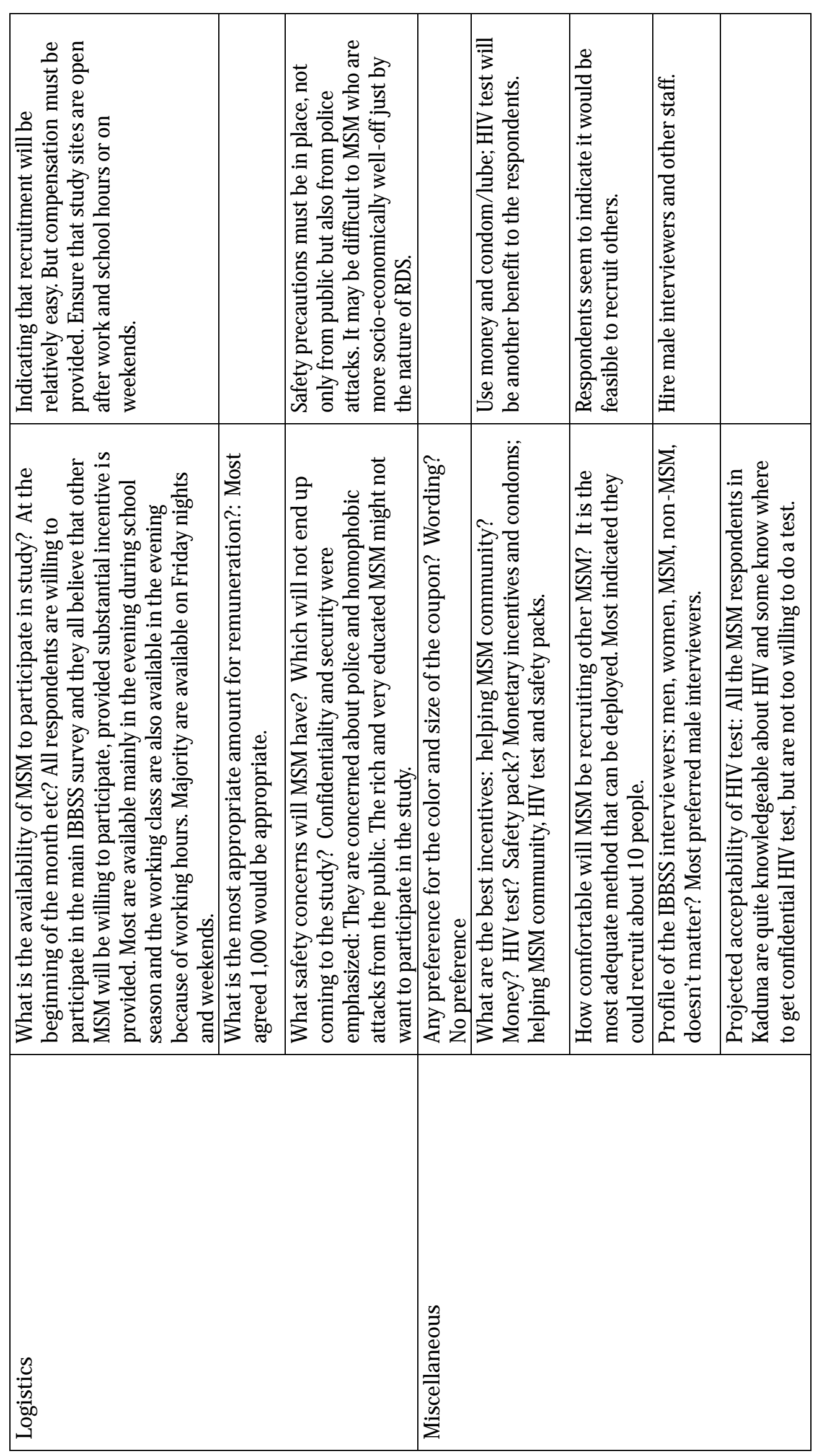




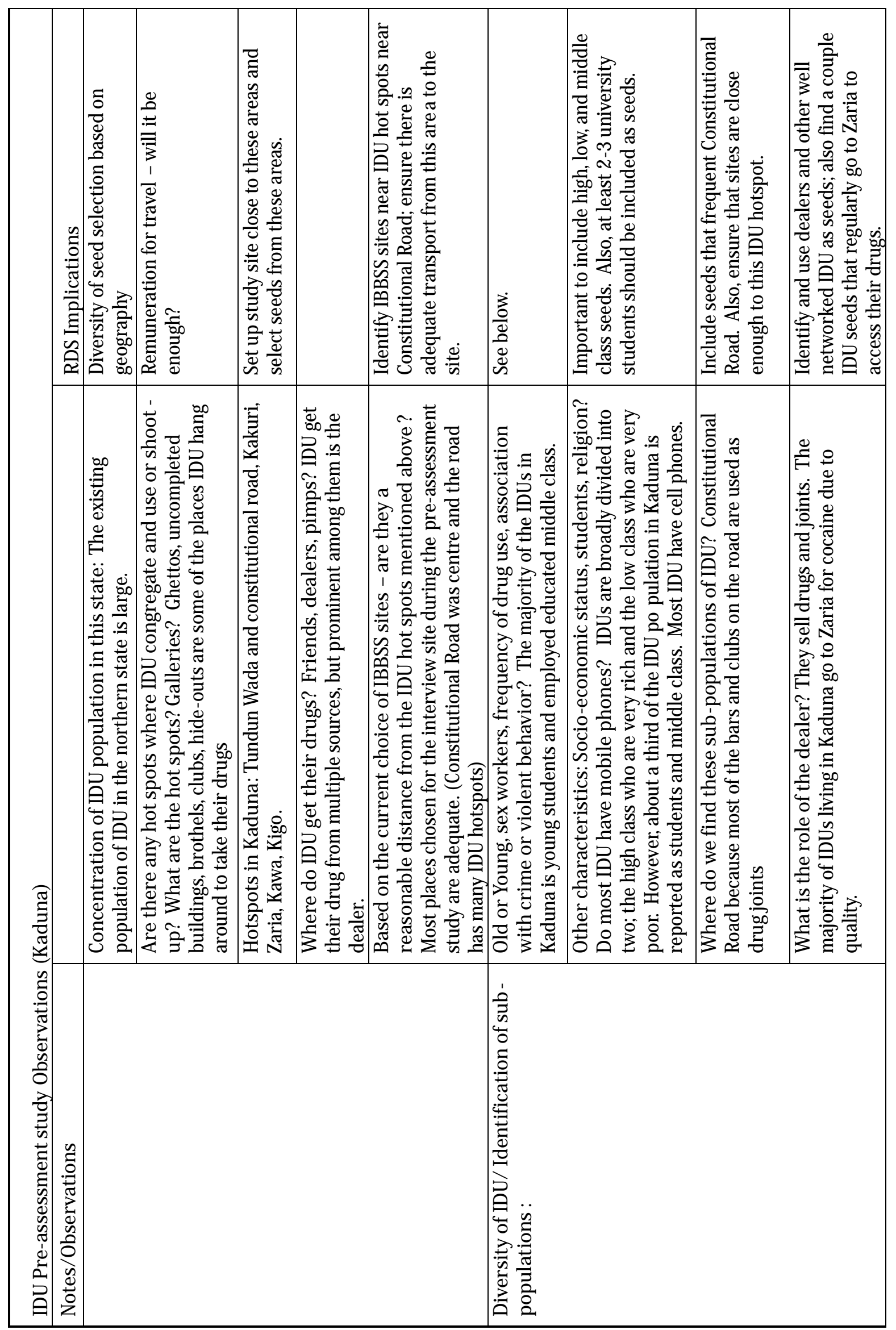




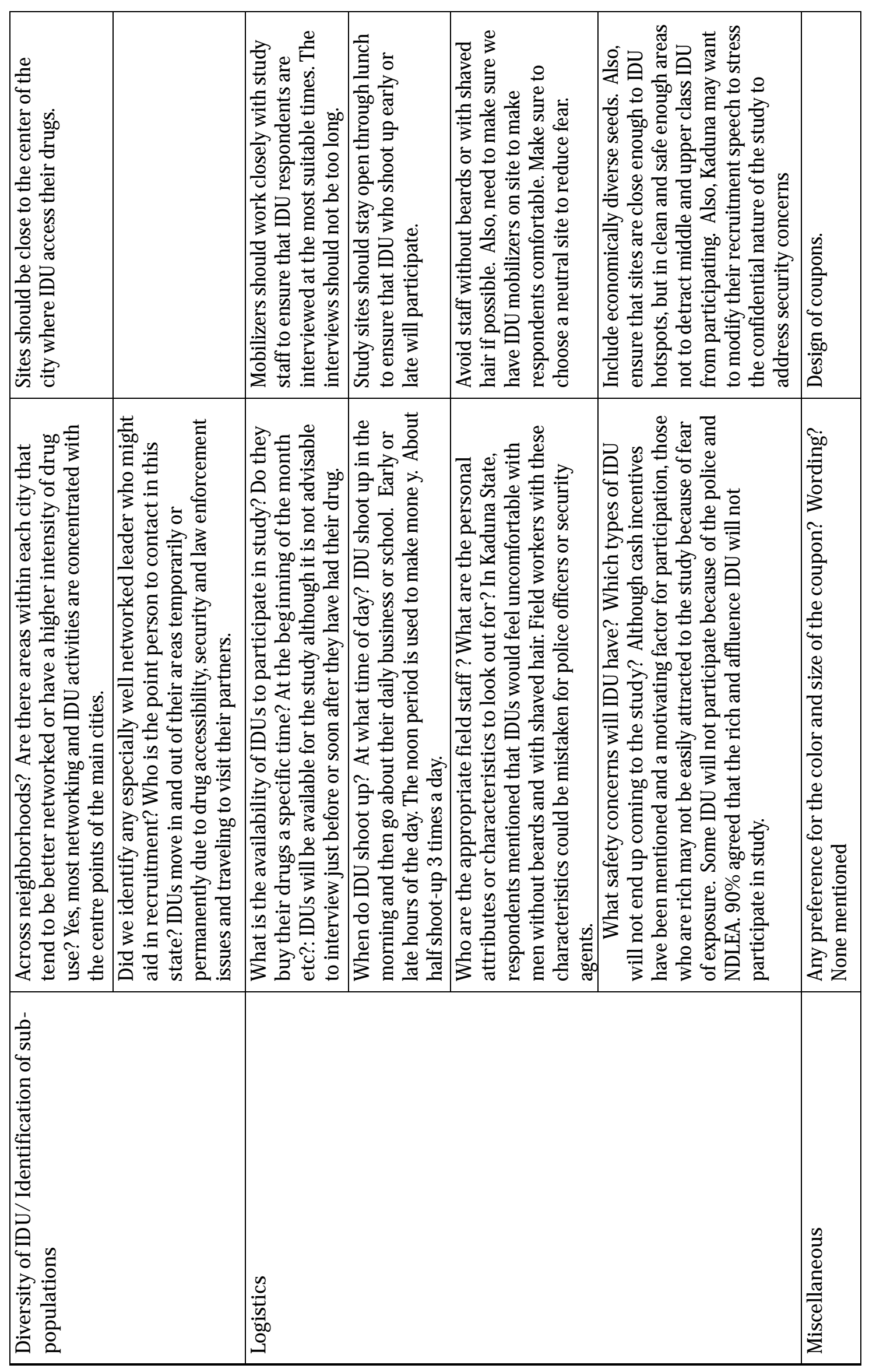




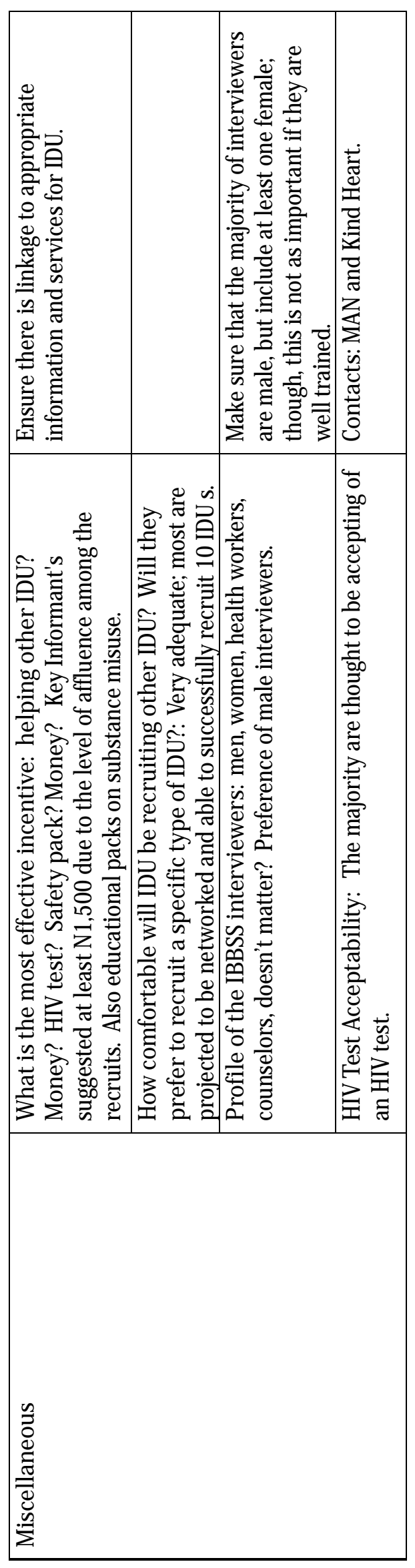




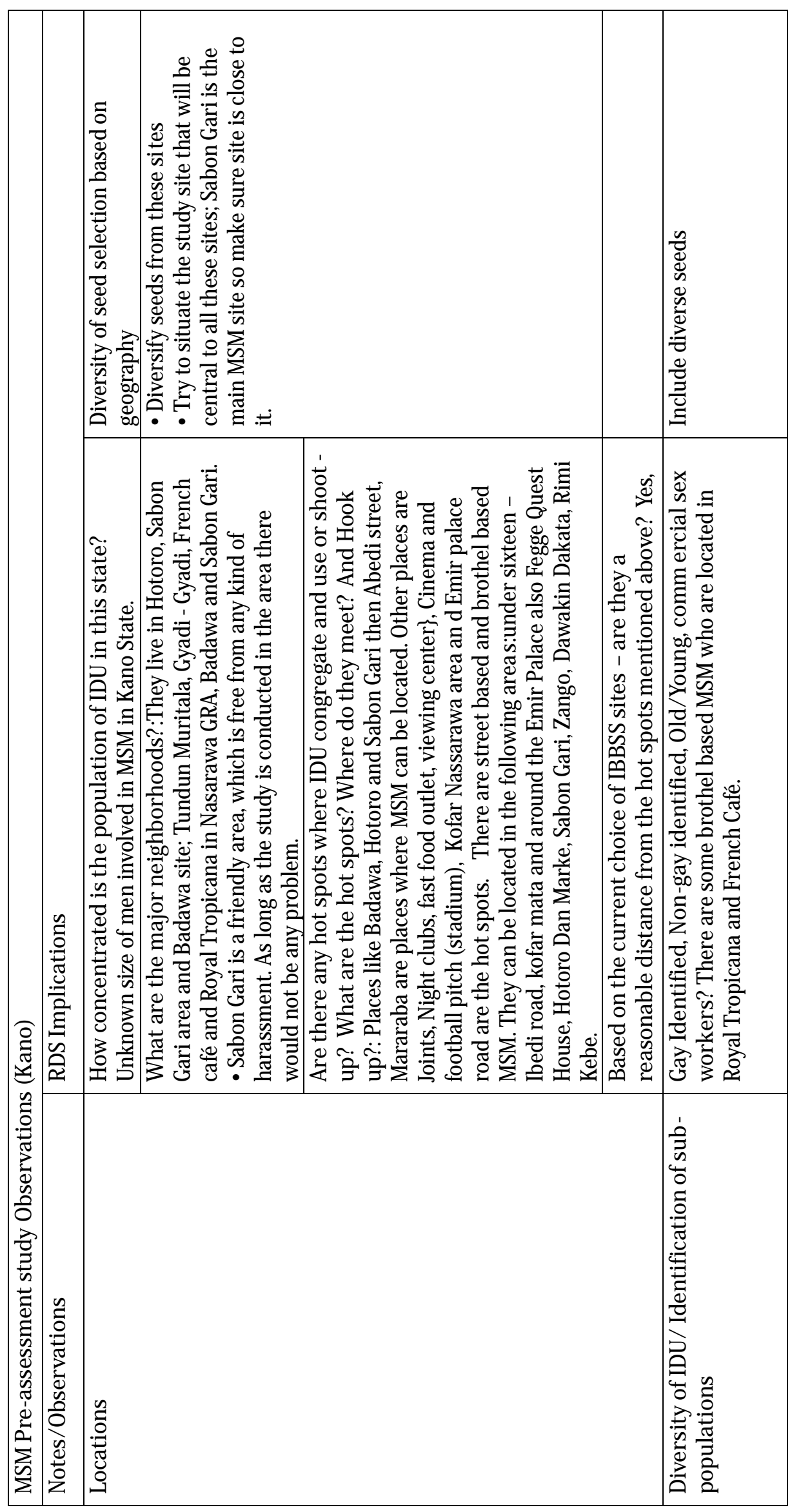




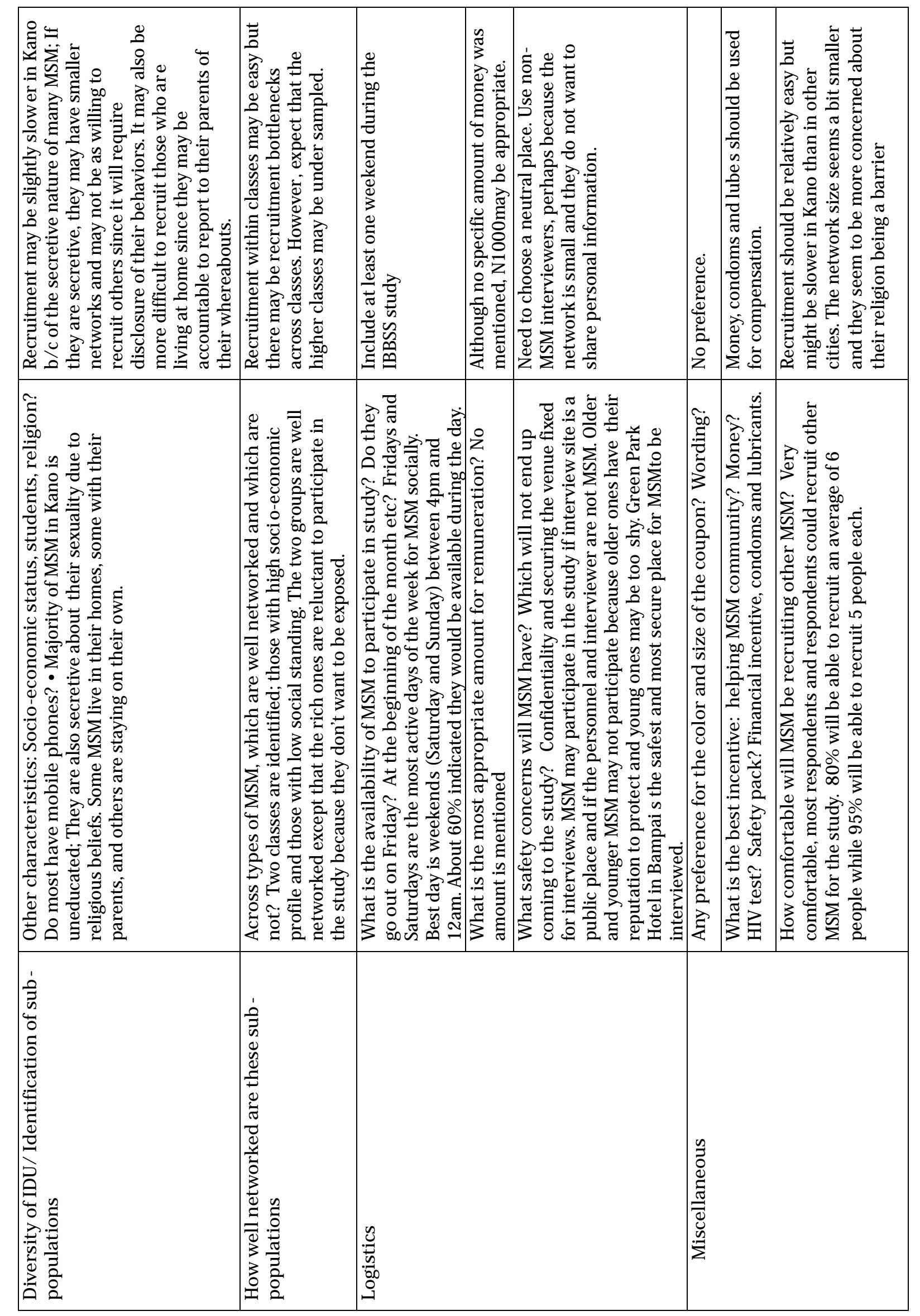




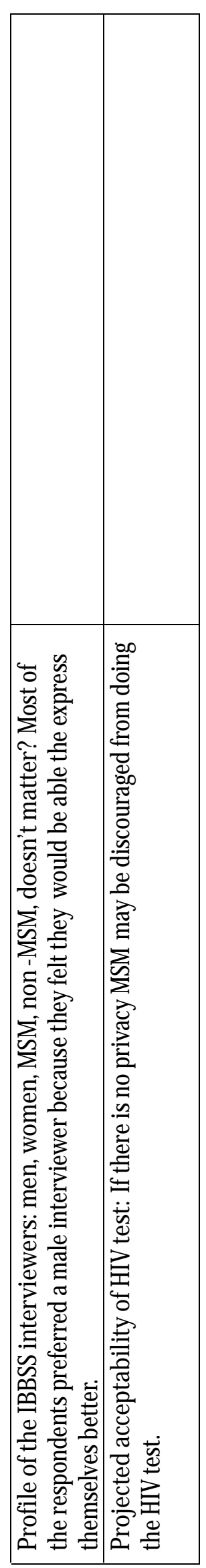




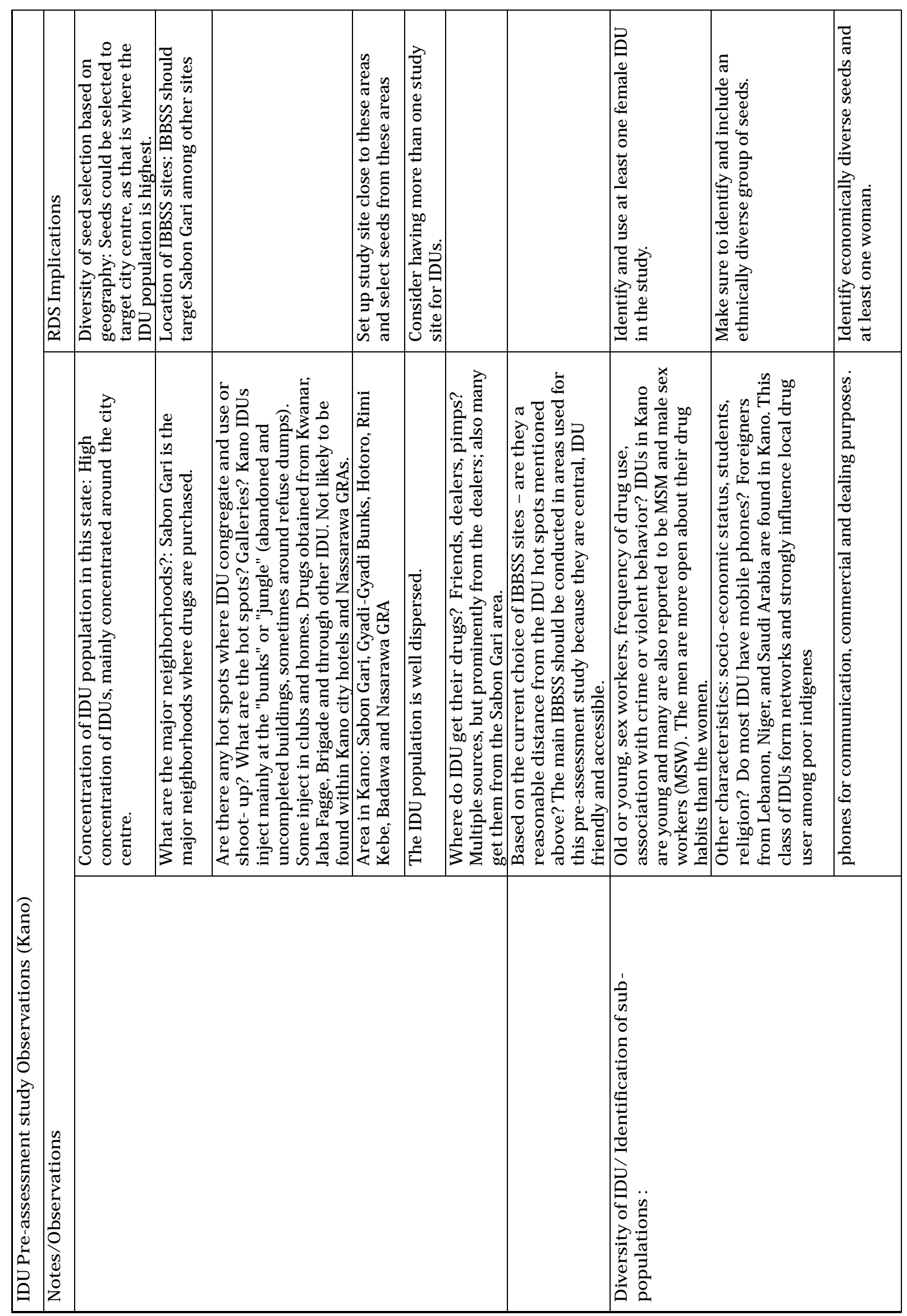




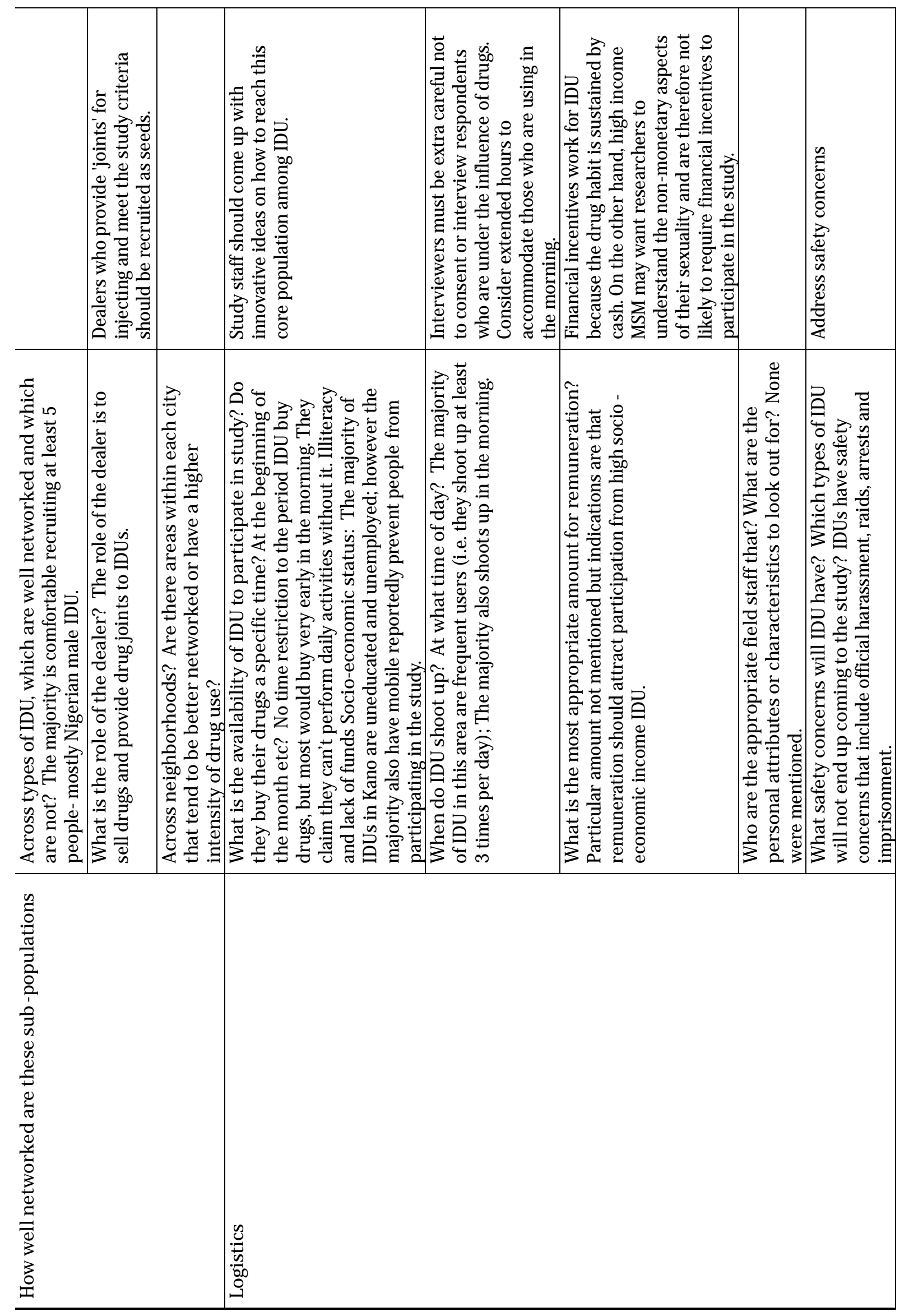




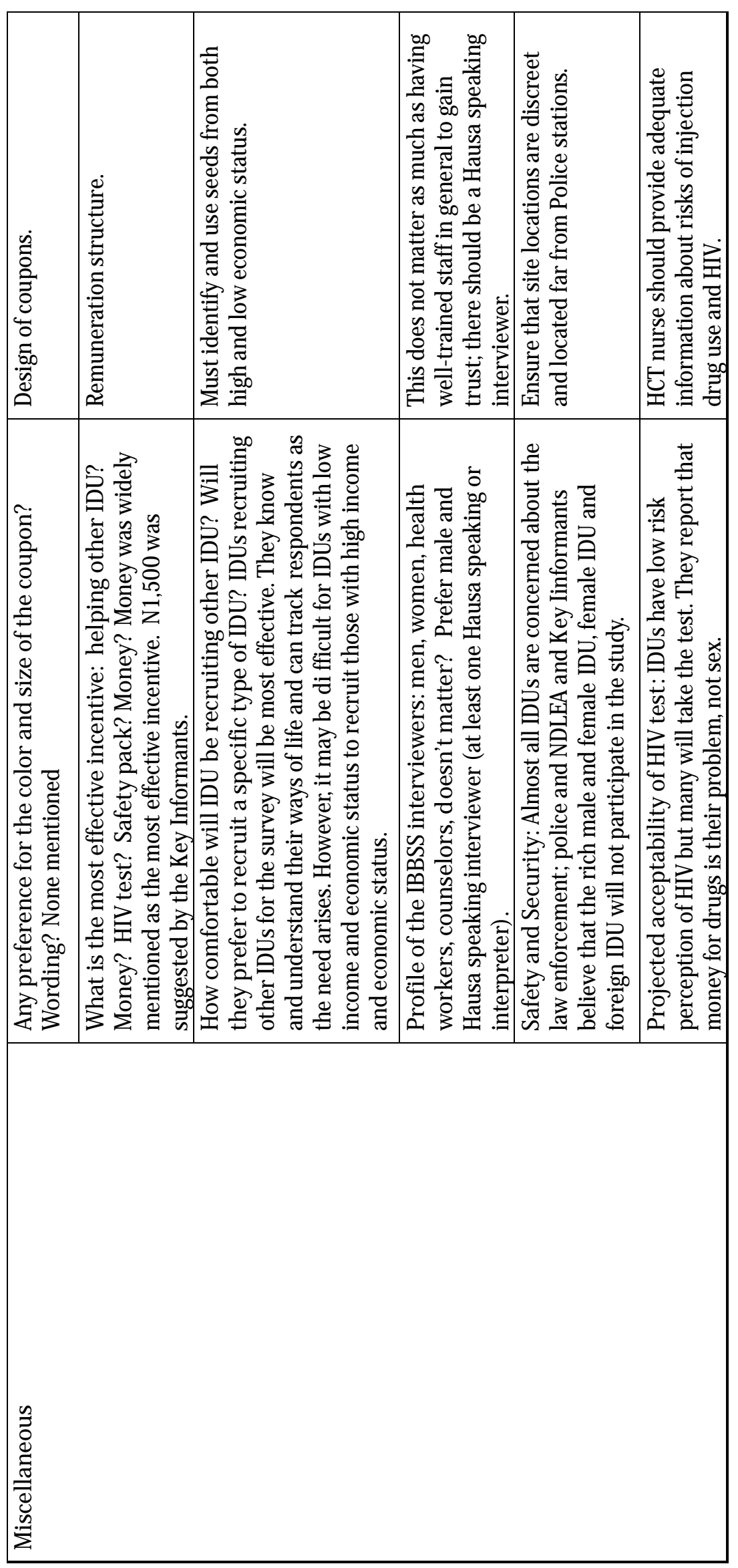




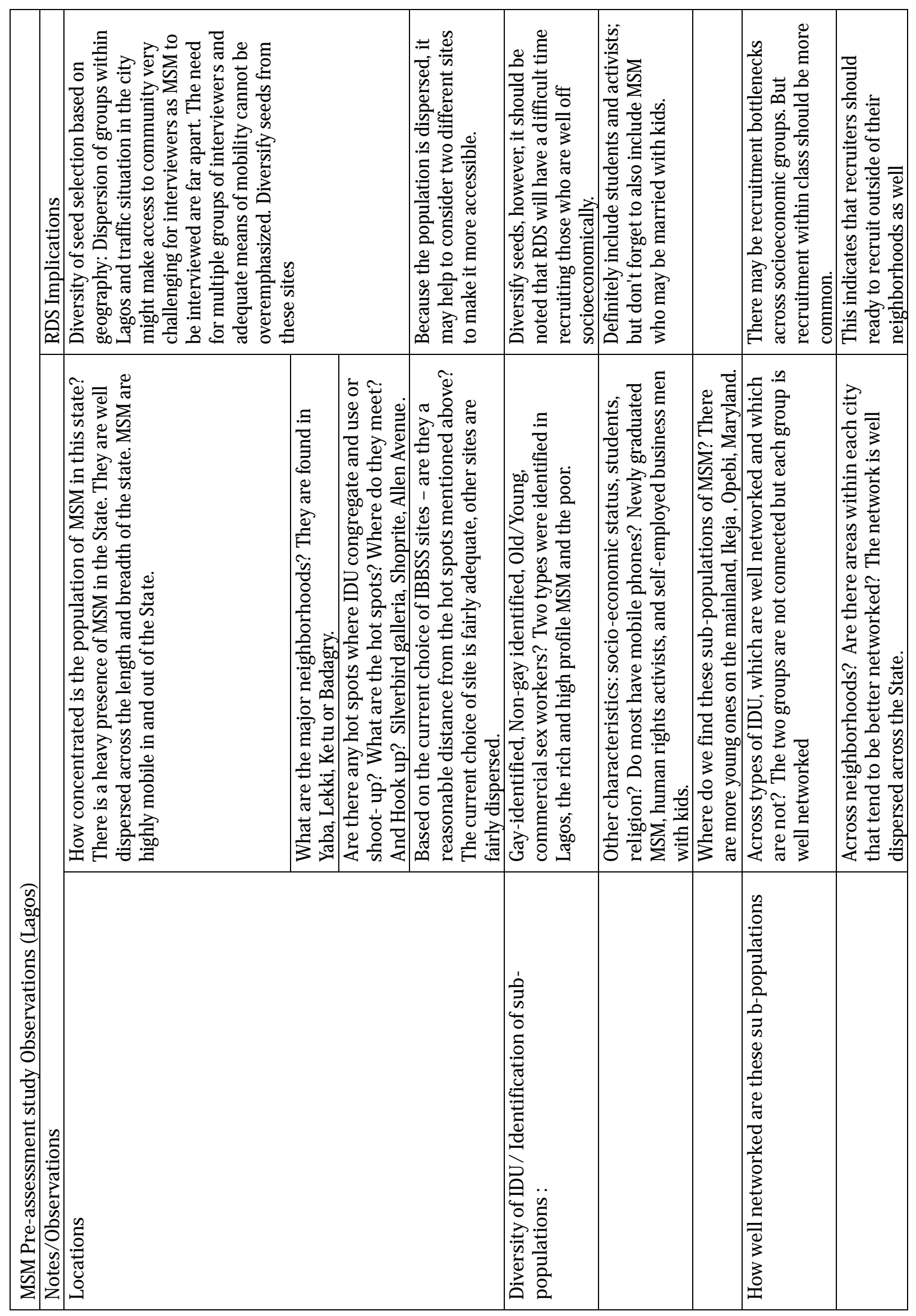




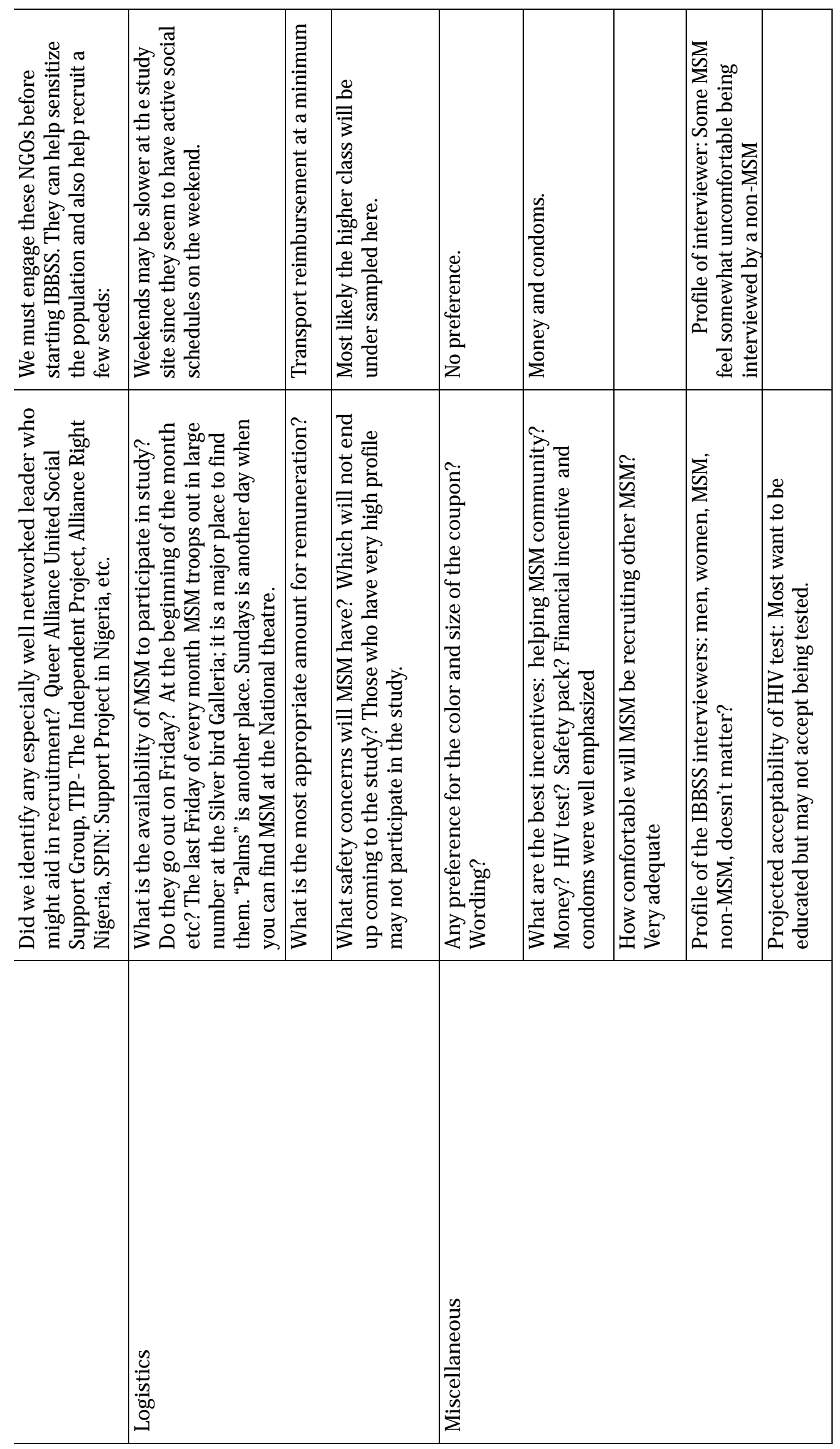




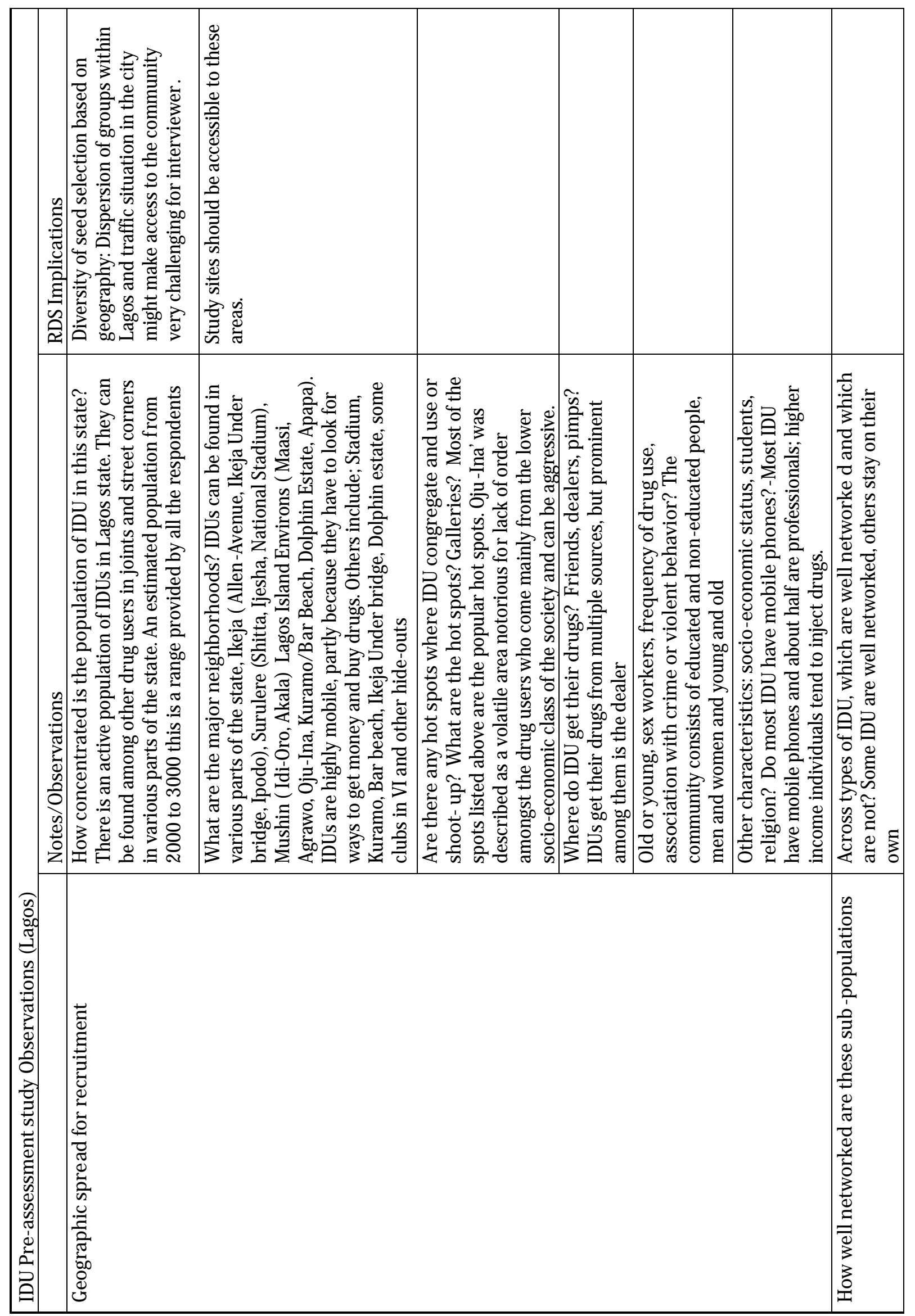




\begin{tabular}{|c|c|c|c|c|c|c|c|c|}
\hline & 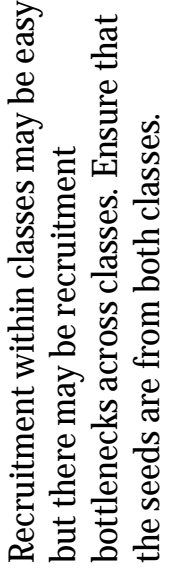 & & 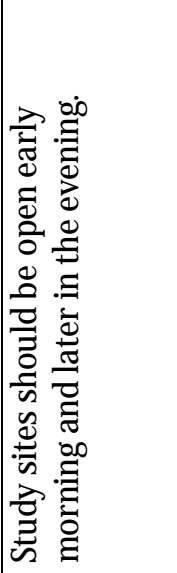 & & & 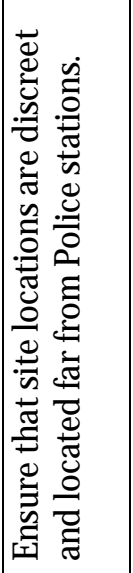 & & 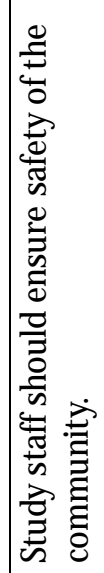 \\
\hline 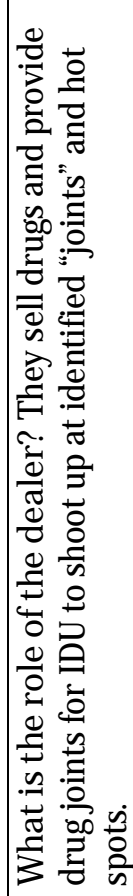 & 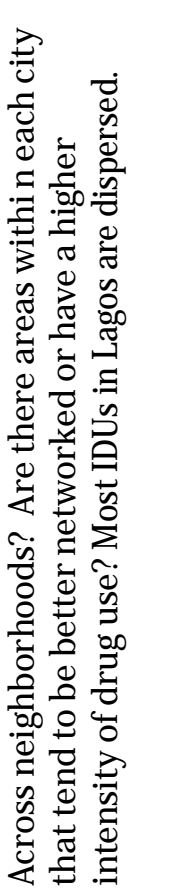 & 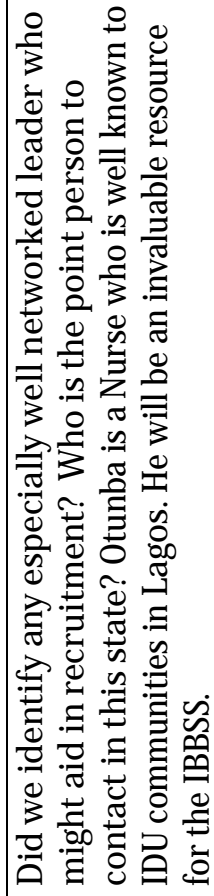 & 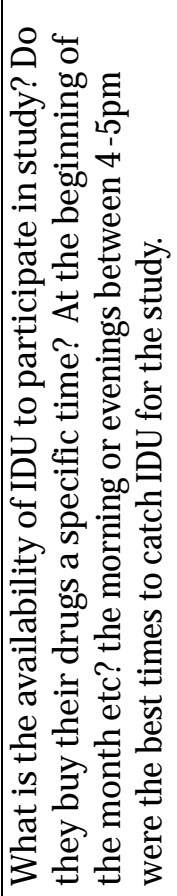 & 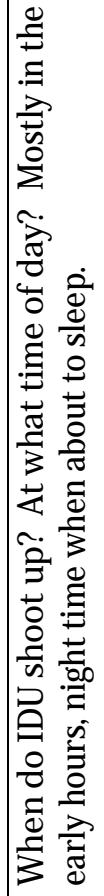 & 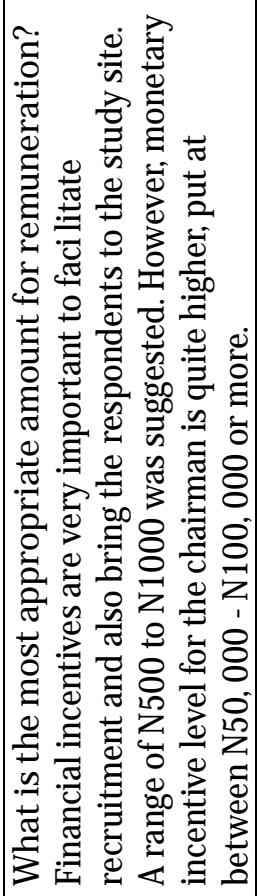 & 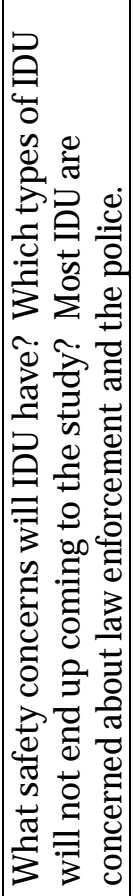 & 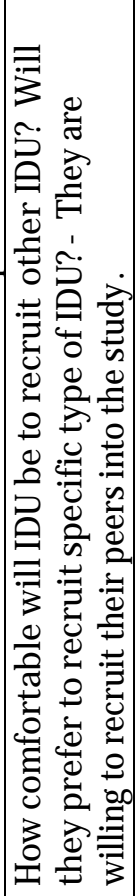 & 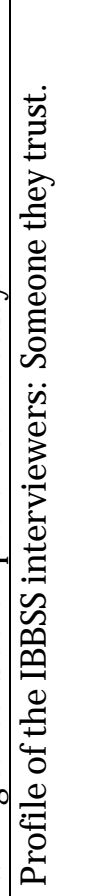 \\
\hline & & & 9 & & & & 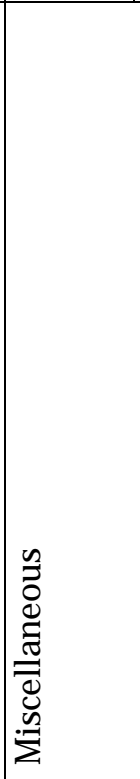 & \\
\hline
\end{tabular}




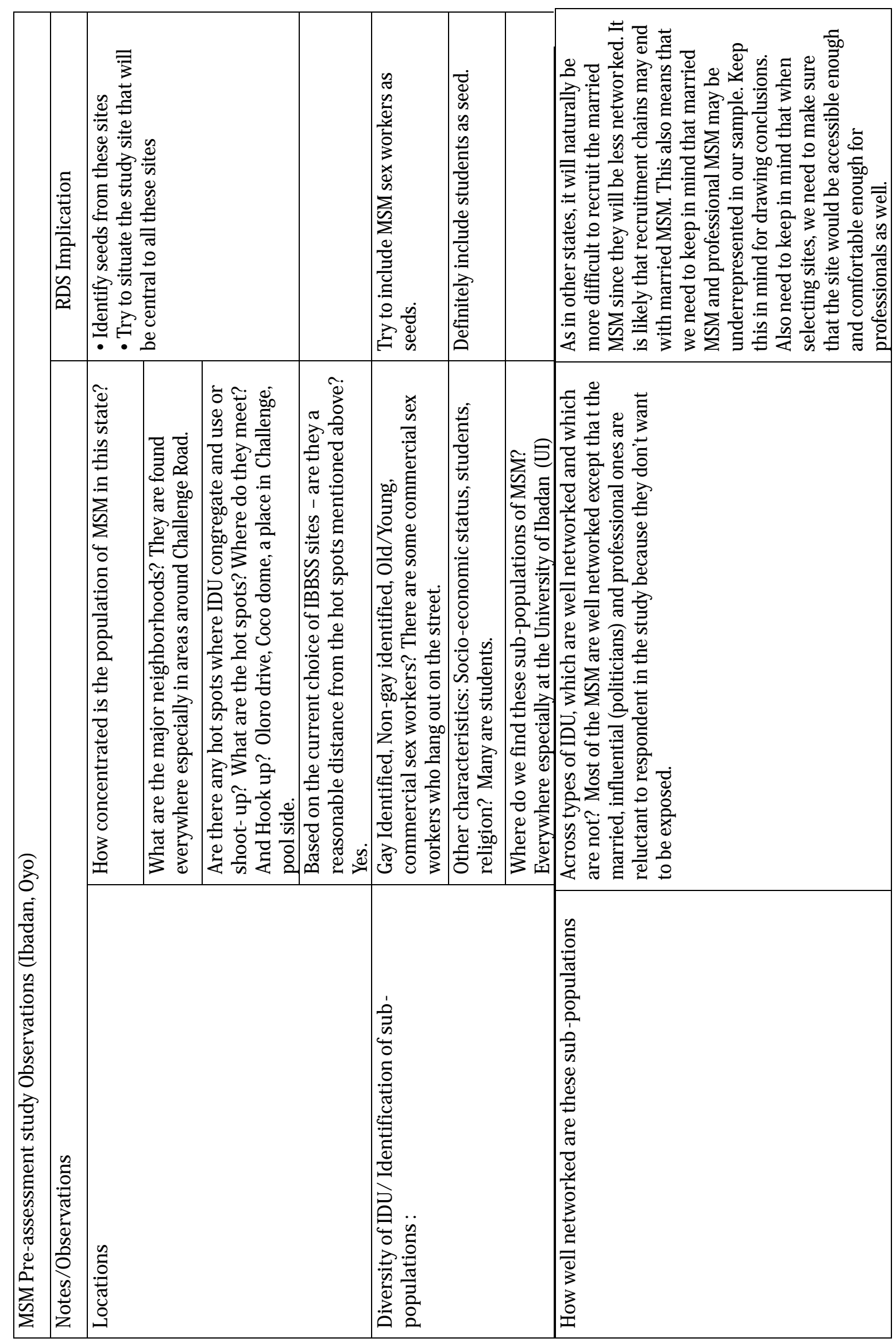




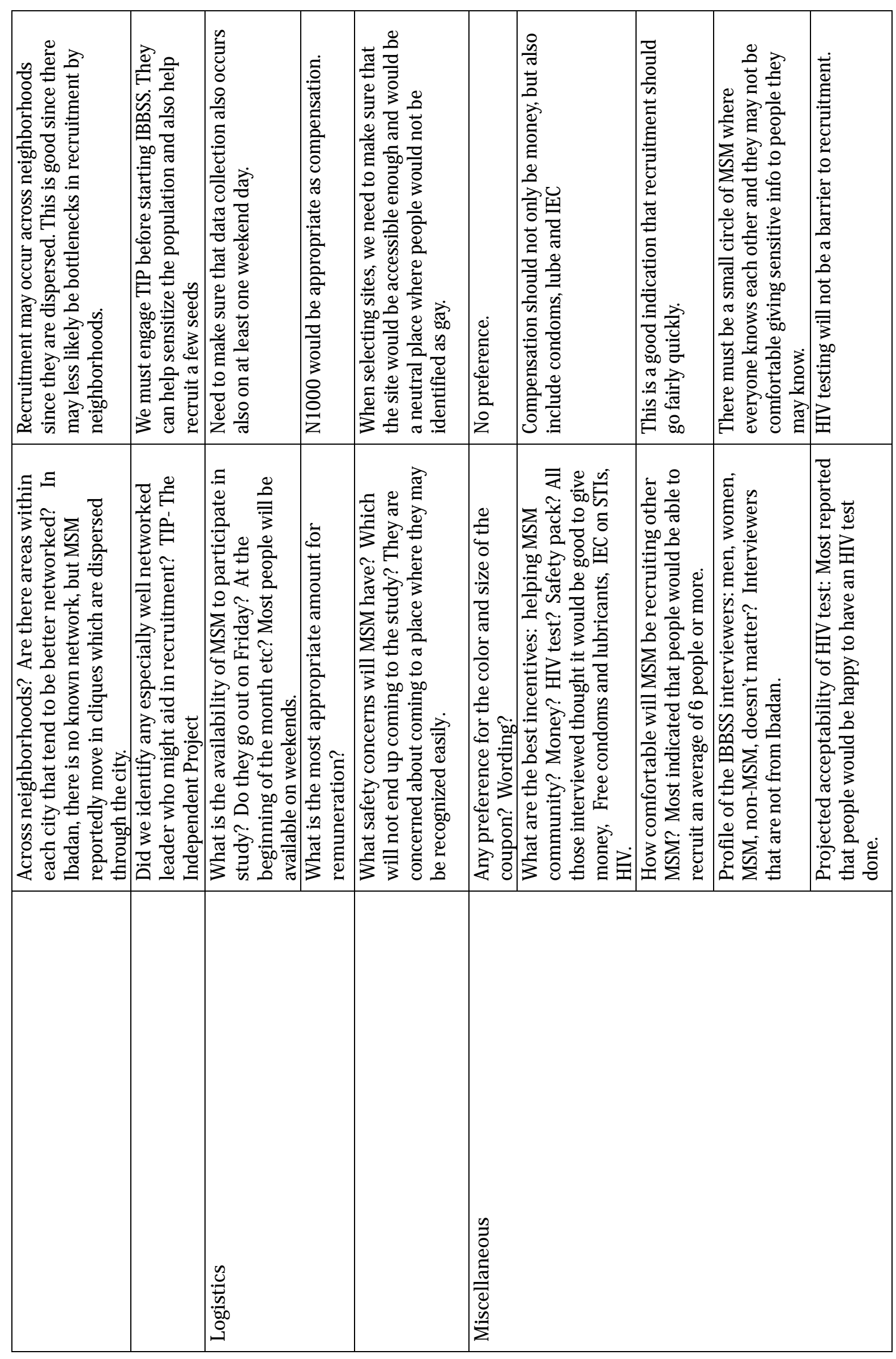




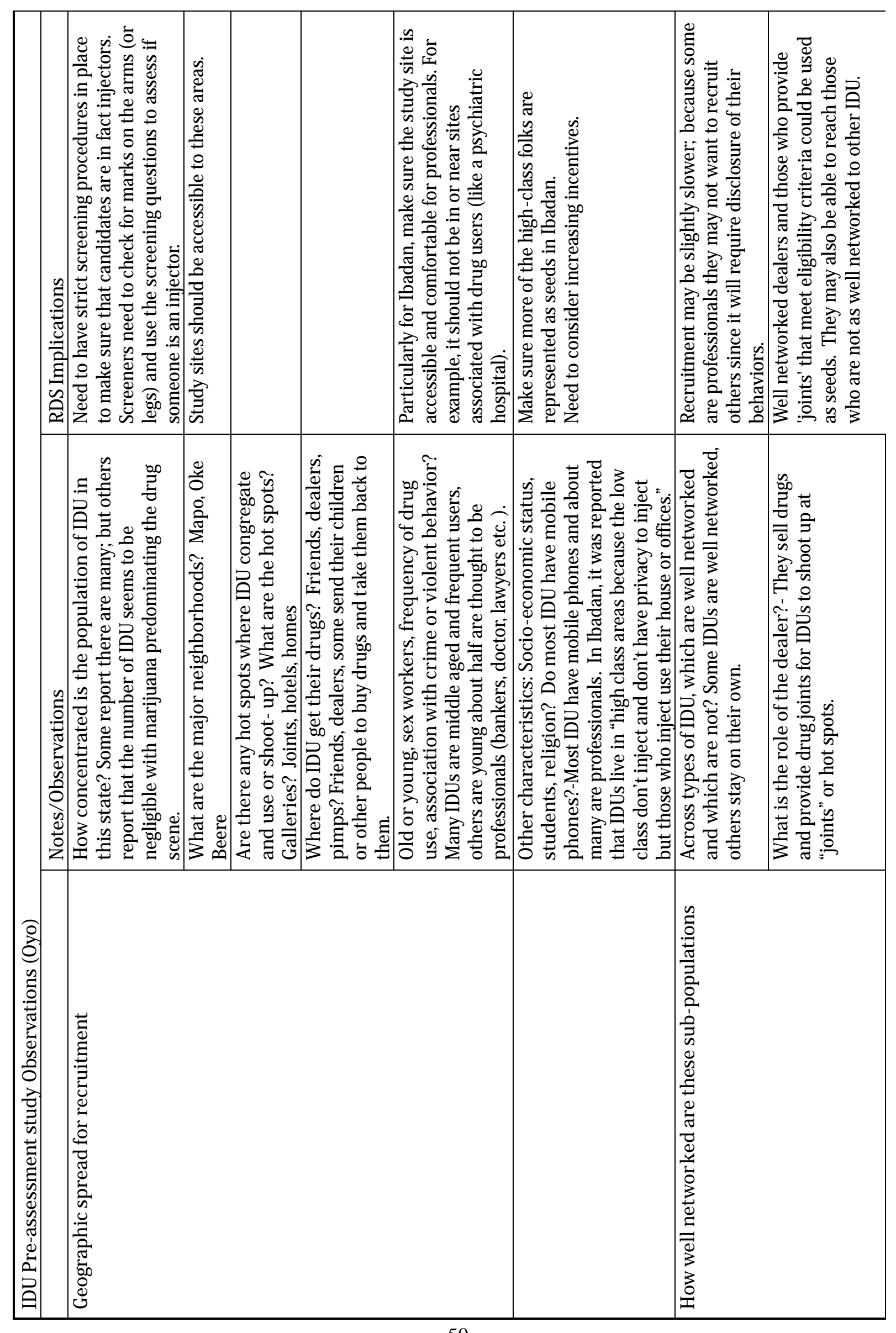




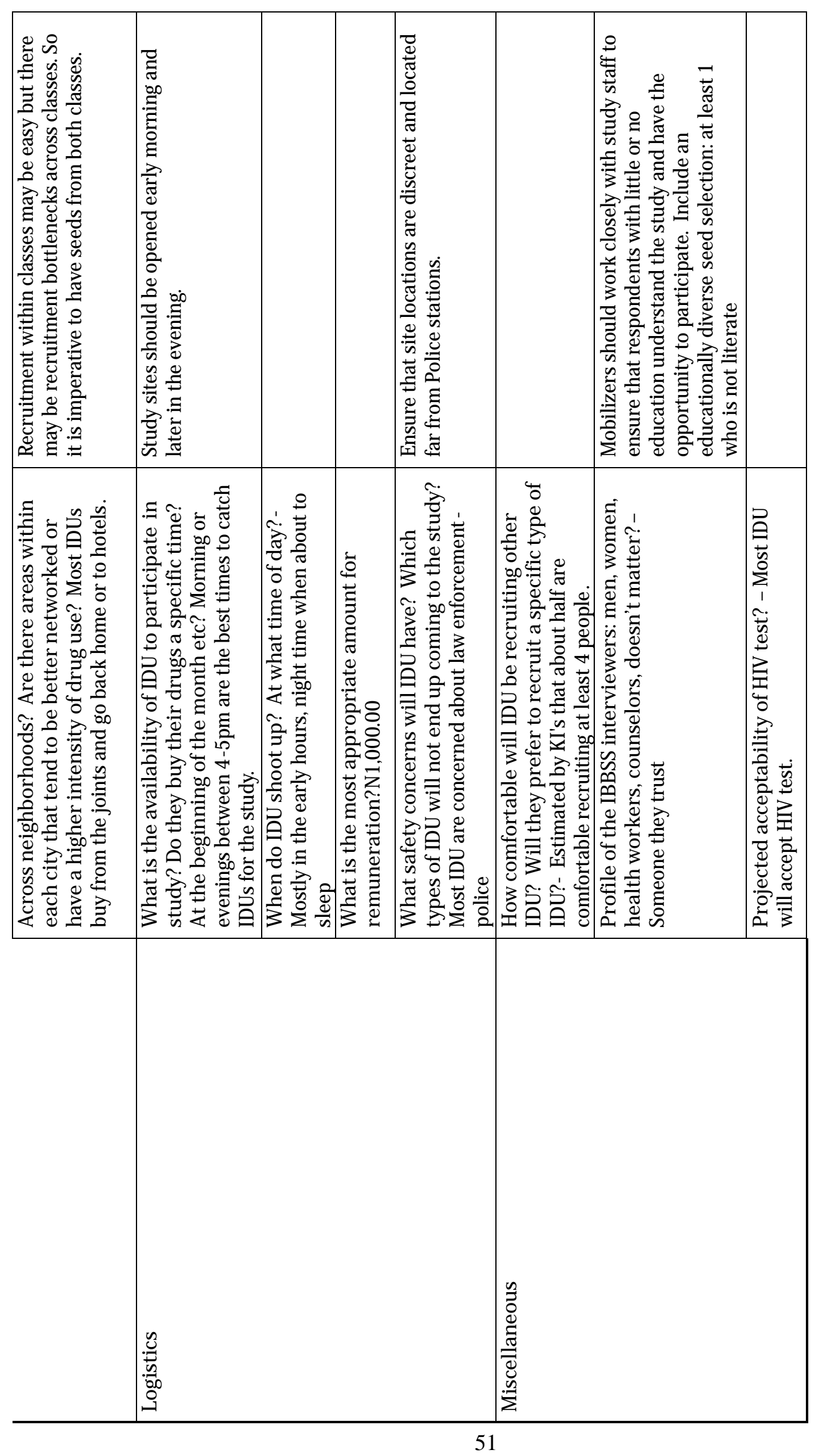




\section{Guidelines for Conducting Formative Research for 2009 IBBSS $^{3}$}

\section{Formative Research}

Formative research is research conducted before the quantitative study begins. Researchers conduct focus groups, in-depth interviews, mapping, or observations of the target population and individuals who work with them to learn more before the study begins. Ethical review for formative research is necessary before collecting data. Researchers who conduct RDS in international settings find that formative research is an essential step in ensuring a successful outcome for the study.

\section{Benefits of formative research}

Aside from learning more about the population under study, formative research may answer questions you have at the beginning of the study and educate the research team about the community they are studying. Formative research can help:

- Decide whether RDS is an appropriate sampling method for the population being studied (is the study population socially networked?)

- Identify sub-populations of interest and help select subsets for seeds

- Identify individual seeds

- Define logistical issues (proper incentive, interview locations and so forth)

- Inform materials development: coupons, survey questions.

\section{Types of formative research}

Types of formative research methods include:

1. Observation - useful for gathering information about the general movements and activities of the target population.

2. Key informant interviews - useful for gathering qualitative data from members of institutions, organizations and government agencies who know something about or work directly with the target population.

3. In-depth interviews - useful for gathering qualitative data from members of the target population.

4. Focus group discussions - useful for gathering information on social networks and pre-testing survey questions and methodological issues.

5. Mapping- useful for gathering information on where target populations spend time.

Table 1 shows questions you may have and how to answer them.

\footnotetext{
${ }^{3}$ Adapted from Guidelines for Conducting Formative Research for Respondent Driven Sampling Among Injecting Drug Users and Sex Workers. Piloted and developed by Lisa G. Johnston, 2006. Some field questions developed by Chomnad Manopaiboon, CDC-Thailand
} 
Table 1: Sample formative research questions.

\begin{tabular}{|c|c|}
\hline Question & How to Find the Answers \\
\hline $\begin{array}{l}\text { Where should we locate } \\
\text { interviewing sites? }\end{array}$ & $\begin{array}{l}\text { Observe and map areas where the target } \\
\text { population spends time. } \\
\text { - Conduct focus group interviews. } \\
\text { - Conduct key informant interviews with } \\
\text { community leaders and peer outreach } \\
\text { workers. }\end{array}$ \\
\hline $\begin{array}{l}\text { What specific language should } \\
\text { we use to identify sexual } \\
\text { behaviors? }\end{array}$ & 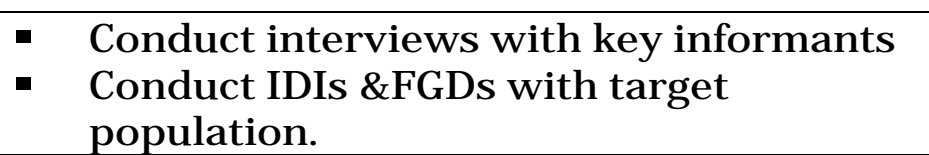 \\
\hline $\begin{array}{l}\text { What kind of an incentive } \\
\text { should we offer? }\end{array}$ & $\begin{array}{l}\text { Use FGDs \&IDIs with of target } \\
\text { population. } \\
\text { Avoid incentives that are too high or too } \\
\text { low. }\end{array}$ \\
\hline $\begin{array}{l}\text { How do we find out more } \\
\text { about the size of the target } \\
\text { population's social network } \\
\text { (network size)? } \\
\text { How can we find out if the } \\
\text { population is properly } \\
\text { networked? }\end{array}$ & $\begin{array}{l}\text { Interview target population with } \\
\text { questions such as: How many people do } \\
\text { you know that are also MSM (or MSM, } \\
\text { youth at risk, others)?How many of these } \\
\text { people have you seen in the past } \\
\text { months (weeks, days)? }\end{array}$ \\
\hline
\end{tabular}

As in all qualitative research, use information from more than one source in order to assess the validity of the information you are getting. This process of combining information from different sources, whether to collect, analyze, present, or interpret the data, is known as triangulation.

Formative Research for 2010 IBBSS

In each pre-assessment location, formative research should be conducted with a convenience sample of up to four key informants each for MSMand IDU categories and four in-depth interview respondents for the two groups, or a combined total of 8 KIIs and 8 IDIs. Information gathering can be conducted with healthcare providers, clinic staff, community leaders, peer educators, social workers, law enforcement, and members of the high-risk group. RDS staff should collect information on several topics and use this qualitative information to make key decisions about the project. Staff should keep detailed notes of all interviews. After each session, staff can review their notes and discuss impressions and themes from interviews. This pre-assessment has IDUs and MSMas target populations. 


\section{A. Injection Drug Users(IDUs)}

An IDU is defined as any person 18 years and above, resident or working in the respective recruitmentarea at the time of the survey, who has injected drugs recreationally at least once in the 12 months preceding the survey.

\section{B. Men who have sex with men (MSM)}

An MSM is defined as any male 18 years and above, resident or working in the respective recruitment area at the time of the survey, who has engaged in oral or anal sexual activities with other men at least oncein the 12 months preceding the survey.

1. Example of inclusion criteria for IDUs - a) injected illicit drugs in the past month; b) aged 18 or older; c) live and/ or work in (name of the province); and d) able to adequately grant informed consent. Demonstrable track marks (stigmata) are commonly used.

2. Example of inclusion criteria for MSM - a) engaged in male to male sex in the past month (or other limited time frame - lifetime activity is discouraged as a non-specific marker); b) aged 18 or older; c) live and/ or work in (name of the province); and d) able to adequately grant informed consent. Additional screening items might include where one meets partners, negotiation of oral or anal sex (who is on top, who goes first).This helps to eliminate misclassification due

\section{Formative Research Questions}

Networksize

\section{a. Why is this question important?}

RDScan only be conducted with a target population that forms social networks. RDSrelies on a recruitment process whereby target population members recruit other target population members whom they know. Social networks can have several formations. For instance, IDUs may inject with, buy drugs from, or socially interact with other IDUs. MSM may know each other by spending free time or working together or by sharing living space.

\section{b. Which questions should be asked?}

How many people do you know, and they know you, you know their name and they know yours, who are also MSM (Have had sex with other another man in the past one year)/ IDUs (injected in the past six months), you have seen them in the past six months and they live in this province? 
How many people do you know, and they know you, you know their name and they know yours who are also MSM (Have had sex with another man in the past one year)/ IDUs (injected in the past six months), you have seen them in the past three months and they live in this province?

How many people do you know, and they know you, you know their name and they know yours who are also MSM (Have had sex with another man in the past one year)/ IDUs (injected in the past six months), you have seen them in the past one month and they live in this province?

\section{c. Which responses will tell methat RDSis appropriate?}

Because RDS relies on peers recruiting peers, it is beneficial that MSM/ IDUs know at least three other MSMor IDUs. Knowing three other MSM/ IDUs ensures that there are a sufficient number of people to whom the MSM/ IDU can give each of his or her three coupons. However, it is best if most of the MSM/ IDUs you interview know up to five, ten, or twenty other MSM/ IDUs for a given time period. This is an indication that the target population has fairly large network sizes. Asking this question for the different time periods (six months, three months and one month) will help in formulating the network question which will be used for data analysis. The network question will be based on the eligibility criteria being used for your study.

Although there are no set rules for which network size works best for RDS, it is suggested that you should use the time period ( 6 months, 3 months or 1 month) which provides network sizes between ten and twenty. For instance, if you interview three IDUs and they say that they have network sizes of 37, 52 and 81, respectively, for those IDUs they have seen in the "past six months", then you may want to ask them about their network sizes for those they have seen in the "past three months". If the same IDUs respond that they have network sizes of 22, 15,18 for those they have seen in the "past three months", then you might want to consider using the time period of three months for the network question that you will use in your survey.

Once you establish that you will use the three month period for your network question, there is no need to ask this question for those MSM or IDUs they have seen in the "past one month".

\section{d. Problems that can arise if this question is notasked}

If the target population has small network sizes (fewer than three), you may not be able to maintain peer recruitment. Small network sizes could indicate that the population from which you are recruiting may be too small or isolated to sustain RDSrecruitment. 
Network density

\section{a. Why is this question important?}

Having large network sizes is an indication of the density of a target population's social networks. Social network patterns should be diverse whereby MSM/ IDUs interact on numerous levels ( socially, cohabiting, when using drugs, during work, etc.)

If collecting provincial level data, MSM/ IDUs being sampled from more than one provincial city will need to be socially networked through the province for RDS to be analyzed. For instance, for provincial level data gathered from MSM/ IDUs at more than one interview site, there will need to be network ties between the seeds and recruits recruited from one interview site and seeds and recruits from another interview site. All participants should have the option of going to either interview site and the addresses of both interview sites should be located on the recruitment coupon. If the MSM/ IDUs in one interview site are not networked to those in another site, then you have two separate samples and they will have to be analyzed as such.

\section{b. Which questions should be asked?}

Use the responses from the questions above ("How many people do you know, and they know you, you know their name and they know yours who are also MSM/ IDUs (injected in the past six months), you have seen them in the past-insert time period here-months and they live in this province?") to find out about network density.

- Could you tell me about how your MSM/ IDU friends interact with each? (What kinds of activities do they do together?)

- $\quad$ Do people who are also MSM/ IDUs make friends with each other?

- Do MSM/ IDUs go out together when they are not working?

- Do you know MSM/ IDUs in [city or province location where sites will be located]? How often do you see these MSM/ IDUs? Under what conditions do you see them?

c. Which responses will tell me that RDSis appropriate?

You want to hear that MSM/ IDUs spend time together doing different types of activities (socializing, injecting, cohabitating, having sex, working, etc.)

You also want to know that MSM/ IDUs are networked throughout the province and that the chances are good that coupons from a seed or recruit from one interview site in the province will begiven to a recruit in another interview site or province.

d. Problems that can arise if this question is not asked.

In one city in Eastern Europe, researchers conducted formative research for an RDSstudy on 
MSM. All funding was in place and tentative dates for conducting this study were scheduled. In contacting organizations working with MSM in the area, it was learned that most of the MSM were trafficked, heavily controlled by agents, and hidden away in brothels. MSM would not attend in-depth interviews and SW agents became suspicious. The researchers quickly learned that MSMwere not able to leave their brothels and did not form social networks with other MSM. Nonetheless, three SW seeds who claimed to know up to ten other MSM where identified and RDSwas attempted in this city.

One seed was interviewed on the start date and given three coupons to use in recruiting other MSM she knew. She never recruited anyone. The other two seeds could not be located for their interviews. The RDS recruitment process did not work because this population did not form dense social networks.

B. Resolve Study Logistics

1. Incentives

a. Why is this question important?

Eligible SW/ IDUparticipants receive a monetary incentive for completing the survey and providing a biologic specimen. Participants can also get an additional monetary reward for recruiting peers (usually up to three). Having an incentive that is too high can result in overcrowding of the interview site, people pretending to be members of the target population just to get the incentive and people buying coupons to sell to others.

Having an incentive that is too low can result in no one participating in the study.

The incentive for MSM should not be confused with payment for their time. The incentive is an enticement, a way to say "thank you", for participating in the study. It is best not to use an open ended question for setting the level of incentive. You should give some figure to the MSM/ IDUs/ key informants that you are interviewing. Get incentive information from numerous sources.

b. Which questions should be asked?

- Do you think NGN is sufficient to encourage MSM/ IDUs to participate in our study (our study includes an interview and a biological specimen, and could take up to one hour to complete)?

- $\quad$ About how much would you expect their transport to the interview site to cost? (You may want to baseyour incentive level on the cost for transportation). 
c. Which responses will tell me that RDSis appropriate?

What you want to hear is that the level/ type of incentive falls with in your study budget.

d. Problems that can arise if this question is not asked.

One study of IDUs in an impoverished country used an incentive that was too high for the target population. This high incentive led to overcrowding of the interview site. IDUs would line up for interviews before the interview site opened its doors each morning. IDUs became belligerent if they did not get interviewed quickly. Some IDUs learned that they could buy coupons and sell them for a profit. Non-IDUs learned how to respond to questions about IDUs and entered the study so they could get the incentive.

Interview Site

a. Why is this question important?

Members of the target population will need to travel to an interview site to enroll and participate in the study. Therefore, RDS interview sites must be accessible, comfortable and appropriate for the target population. It is important to speak to members of the target population to determine the most suitable interview site for your RDSstudy.

b. What questions should be asked?

If you have an interview site selected, then ask:

- Would you feel comfortable coming to to participatein a study?

- Do you think other MSM/IDUs would feel comfortable coming to to participatein a study?

- Why or why not?

If you do not have an interview site selected, then ask

- Where do you thing would be a location for an accessible, comfortable place for MSM/ IDUs to go to participate in a study?

- How many sites do you think are necessary for a city/ town of this size? If more than one site is suggested, where do you think these sites should be located? 
- What are the characteristics of an interview site (somewhere will you will be interviewed and haveblood taken) that would make it mostcomfortable?

- What do you think other MSM/ IDUs would say are the characteristics that would make an interview site most comfortable?

Other questions to ask:

- What are the most convenient times of the day for MSM/ IDUs to go to an interview site to participate in a study?

- Which days of the week do you think MSM/ IDUs would be most likely to go to an interview site to participatein a study?

- Do you think IDUs and MSMwould be willing to be interviewed at the same interview site at the same time (important to know if you are having simultaneous studies)?

c. What responses will tell me that RDSis appropriate?

Appropriate responses will depend on what is needed for your study. What you want to hear is that the interview sites you have available are those that MSM/ IDUs will feel comfortable to going to. If MSM and IDUs are unwilling to attend the same interview sites, then you may have to use separate interview sites or sample these two groups at different times.

d. Problems that can arise if this question is not asked.

In one study, IDUs and SWs were being interviewed for the same study at the same interview site. After eight weeks this study attained its sample of IDUs, but only enrolled a handful of SWs. It was later learned that SWs were not willing to go to the same interview site as IDUs. The research team had to extend its study duration to sample SWs once the IDUs were sampled and no longer visiting the interview site. If an interview site is not accessible or is located in an area that is not comfortable to the target population, then no one will enroll in your study.

Materials

a. Why is this question important?

IBBSS uses materials that are important to the study. For instance, the design of the referral coupons could be improved if you have input from members of the target populations. MSM/ IDUs could provide information about appropriate coupon color, size, and content.

The IBBSS is an opportunity to provide educational materials to MSM/ IDUs. It could be 
helpful to ask MSM/ IDUs about the types of educational materials and supplies (condoms) they would be mostinterested in receiving.

b. Which questions should be asked?

- You will be given coupons which you will use to recruit other MSM/ IDUs. Do you have a preference of what color these coupons should be? These coupons are about the size of ___ do you think they should be smaller or larger? What kinds of information do you think we should put on the coupons? Do you think a map on the coupon will be helpful for finding the interview site?

- We would like to offer educational materials/ supplies to MSM/ IDUs who participate in the study. What health topics are of most interest to MSM/ IDUs? Do you think MSM/ IDUs will review written materials on these subjects? Do you think MSM/ IDUs be interested in receiving free condoms? Is there anything else about which MSM/ IDUs would want to receive information?

c. Which responses will tell me that RDSis appropriate?

Appropriate responses will depend on what is needed for your study. What you want to hear is that the suggestions made by MSM/ IDUs can be implemented for or incorporated into your study.

d. Problems that can arise if this question is not asked.

If these questions are not asked, there may not be uptake of the coupon recruitment system. If MSM/ IDUs suggest having a map on the coupon and no map is included on the coupon, MSM/ IDUS may have trouble finding the interview sites. In some areas some colors may be offensive to MSM/ IDUs.

IBBSS offers an excellent opportunity to provide important health information to MSM/ IDUs. This opportunity could be lost if educational materials and supplies requested by MSM/ IDUs are not provided.

\section{Identify Seeds}

Choosing the proper number and types of seeds will be highly dependent upon the information collected during formative assessment. During formative assessment, staff may also have the opportunity to identify people who would be good seeds. Though seed selection may occur during the formative assessment period, it can also happen through other methods just prior to implementing data collection. 


\section{Seed selection}

\section{a. Why is this question important?}

Seeds are extremely important to IBBSS recruitment. Seeds are non-randomly selected members of the target population who initiate the RDS recruitment process. Seeds should be well connected (have large network sizes) to other members of the target population. The best seeds are those who understand the project, support its goals and objectives, and can accurately and enthusiastically persuade others to participate.

The appropriate number of seeds is dependent to some degree on local resources and other issues identified during formative assessment (e.g. presence of sub-populations), as well as the sample size. Seeds may be selected from Voluntary Counseling and Testing (VCT) sites, local organizations that work with the high-risk population (e.g. needle exchange program), or through contacts made by peer educators or social workers. Seeds recruited by peer educators or social workers may be recruited at popular public locations such as street corners, parks, bars and other sites.

b. Which questions should be asked?

Questions to ask key informants:

- Can you think of any MSM/ IDUs who would make good seeds (who know a lot of other MSM/ IDUS, speak well, are well-liked by their peers, and would be interested in our study goals)?

- How many of these types of MSM/ IDUs can you identify for us?

- Can you think of MSM/ IDUs who are diverse with respect to geographic location (not all MSM or IDUs who work/ live in the same neighborhood), age, income, type (for MSM you want different types, such as street, karaoke and home based; for IDUs you want long term and shortterm injectors), etc.

- If we wanted to find MSM/ IDUs for the study we are planning, what would be the best way to locate them? (e.g. through clinic staff, direct identification at SW/IDU locations, through NGOs)

- Do the MSM/ IDUs have an association? Have any of the previous outreach programs used MSM to reach out to other MSM/ IDUs? If yes, can you help us to contact these MSM/ IDUs?

- When you do outreach, what contact do you have with establishment owners or other 
authorities? The police? Have you had difficulties with getting access to MSM/ IDUs because of any of these kinds of authorities?

Questions to ask target populations (keep in mind that those target population members who are willing to speak to you for formative research, may make good seeds):

Can you think of any MSM/ IDUs who would make good seeds (who know a lot of other MSM/ IDUS, speak well, are well liked by their peers, and would be interested in your study goals)?

- Would you describe yourself as having the characteristics of a good seed?

- How many of these types of MSM/ IDUs can you identify for us?

- Can you think of other MSM/ IDUs who are diverse with respect to geographic location (not all MSM or IDUs who work/live in the same neighborhood), age, income, type (for MSM you want different types, such as street, karaoke and home based; for IDUs you wantlong term and short term injectors), etc.

- If we wanted to find MSM/ IDUs for the study we are planning, what would be the best way to locate them? (e.g. through clinic staff, direct identification at SW/ IDU locations, through NGOs)

- $\quad$ Do the MSM/ IDUs have an association? Have any of the previous outreach programs used MSM/ IDUs to reach out to other MSM/ IDUs? If yes, can you help us to contact these MSM/ IDUs?

c. Which responses will tell methat RDSis appropriate?

Appropriate responses will depend on what is needed for your study. What you want to hear is that diverse seeds can beidentified and are willing to participate in your study.

d. Problems that can arise if this question is notasked.

In one study, the seeds that were selected were not well-connected to their peers and did not understand the study goals. These seeds ended up not recruiting their peers and new seeds had to be selected two weeks after the study started. This ended up costing the project more money as they had to extend the study by two weeks.

In another study, seed diversity was overlooked. IDU females were not used as seeds although IDU females were eligible to participatein the study. Once the sample was gathered, no IDUfemales had been recruited into the study. 
D. Other types of questions to understand your target population

1. Geographic understanding

a. Why is this question important?

Questions about geographic locations where the target population work and spend time could help in identifying seeds, interview sites, and in understanding MSM/ IDUs better.

b. Which questions should be asked?

Questions to ask key informants:

Can you describe the areas where you and your team do outreach to MSM/ IDUs? (May want to specify: direct establishments, bars/karaoke/restaurants, parks or other street locations.)

2. Types of sex work for MSMand injecting practices for IDUs

a. Why is this question important?

Questions about the types of MSM or injecting practices of IDUs could help in identifying seeds, developing the questionnaire and in understanding MSM/ IDUs better.

b. Which questions should be asked?

- What are the different types of MSM (e.g., brothel, street, karaoke, home based)? What are the most prevalent types of SW? How do you define "direct" and "indirect" MSM? How doyou tell if someone who works at an "indirect" establishment is a SW?

- Do you think the MSM who work at a venue also sometimes work outside the venue like at a street or in a park? Probe for the mobility of MSM both within and among cities. Is it common for someone to work in multiple sites? Within what period of time? Do MSMknow people who work in different types of sites?

- $\quad$ Are their foreign (or other subpopulations) MSM living in this area? If so, do they comprise a large group? Do they speak the local language(s)?

- How much do the different types of MSMearn for sexual intercourse? For oral sex? For other types of sex?

- $\quad$ Are there different types of IDUs? If so, what are the different types of IDUs? 
- $\quad$ Are their foreign IDUs (or other subpopulations) living in this area? If so, do they comprise a large group? Do they speak the local language(s)?

- Do you think IDUs move around the province? Probe for the mobility of IDUs both within and among cities. What are the reasons that IDUs are mobile?

- Do maleand female IDUs know each other?

c. Which responses will tell me that RDSis appropriate?

Appropriate responses will depend on what is needed for your study. What you want to hear is that your interview site is equipped with the appropriate staff and that your seeds are adequate for your study needs.

d. Problems that can arise if this question is not asked.

In one study of MSM in Asia, deaf and foreign MSM showed up at the RDS interview site to participate in the study. However, no formative research had been conducted and the researchers did not know that these sub populations existed. The interview site was not equipped with interviewers who knew sign language/ or how to communicate with the deaf MSM or who could speak the languages of the MSM from foreign countries. As a result, these important sub-populations could not participate in the study and important information about services and HIV risk factors were not collected from these MSM.

3. Clinic services

a. Why is this question important?

Some RDSstudies will offer vouchers for clinic services. Questions about clinic services can help inform you about where to send MSM/ IDUs for HIV VCT and STI services. These questions can also be useful for developing the questionnaire, study design and contents for your educations materials packet.

b. Which questions should be asked?

Questions to ask key informants:

- Do you think MSM/ IDUs have a lot of STIs and HIV? What do you think is the prevalence of STIs and HIV among MSM/ IDUs in this area?

- Do you think certain types of MSM/ IDUs are at more risk for STIs/ HIV? Please 
describe.

- Do your staff do outreach to MSM for education, condom distribution, or to encourage them to come to the clinic for screening? How often? What kinds of venues to you go to? (Probe for parks, other locations where street MSM spend time.)

- With the survey we are planning, we want to make sure that the places and times are convenient for MSM to attend for interviews. What are the normal working hours here? Do MSM find it easy to get here on public transport? Would staff be able work at this site in the evenings for about a two-month period? If MSMprefer not to come to a clinic, do you have other suggestions for a convenient location where interviews and specimen collections could be done?

- How feasible would staffing befor that kind oflocation?

- We plan to collect oral fluid for HIV testing and urine for STI testing in the upcoming survey. Where do you usually send lab specimens? What are your usual systems for storing, processing, and transporting specimens?

Questions to ask members of the target population:

- Do you think MSM/ IDUs have a lot of STIs and HIV? What do you think is the prevalence of STIs and HIV among MSM/ IDUs in this area?

- Do you think certain types of MSM/ IDUs are at more risk for STIs/ HIV? Please describe.

- Do you know where you can go to get a confidential HIV test and results? STI exam and results?

- Have you ever had an HIV test/ STI exam? If so, where? Did you get your results? Did you get treatment? How did the staff treat you? Did the staff know you were a SW/ IDU?

- Would you be willing to go to if we gave you a voucher for a free HIV test/ STI exam? Why or why not?

c. Which responses will tell me that RDSis appropriate?

Appropriate responses will depend on what is needed for your study.

d. Problems that can arise if these questions are notasked. 
- $\quad$ referral sites)? Do you think you will be comfortable sharing the same clinic with clients for interview? Do you think the clients will becomfortable?

- If part of the survey includes taking an HIV test, how likely do you think it is thatyour friends wouldjoin? What aboutyou?

- What if we also askyou and your friends to screen for other STIs?

c. Which responses will tell methat RDSis appropriate?

Appropriate responses will depend on the design of your study.

d. Problems that can arise if these questions arenot asked.

By not asking these questions, you may design your study in a manner that is not acceptable to the target population. You may find out that the target population will not attend a study that requires a biological specimen or that conducts an STI exam.

Or, you may find that your target population will be willing to provide biological specimens when it was believed they would not. This happened in an African country during a study of males with high risk behaviors. The public health authorities strongly believed that this population would not attend a study that took blood (finger prick) from them for HIV testing. Despite numerous "authorities" claiming that having a biological component to the RDS study would not work, the RDS research team held focus groups to ask members of the target population. Information from the focus groups indicated that these men would be very interested in having the HIV test and many of them would also be interested in receiving their HIV results. The RDS study was redesigned with a biological component and has a high percentage of participants providing blood spots and many of these men receiving HIVinformation and testresults.

\section{Formative IBBSSAssessment with MSM}

In-depth Interview Guide

DESCRIBE PURPOSE OF STUDY, HIGHLIGHTING ITS LINKAGE WITH THE 2009 IBBSS, AND SOLICITING COOPERATION FOR BOTH ACTIVITIES. ASSURE OF CONFIDENTIALITY, ADMINISTER CONSENT, AND CREATE COMFORTABLE ATMOSPHERE. DESCRIBE ORGANIZATION OF DISCUSSION AROUND CORE ISSUES AND THAT THE ENTIREDISCUSSIONSHOULD LAST LESSTHAN2 HRS.

THIS GUIDE WILL BE USED TO EXPLORE OPERATIONAL ISSUES RELATED TO DATA COLLECTION USING RDS (I.E., WILLINGNESS TO RECRUIT, SIZE OF PERSONAL NETWORKS, INCENTIVE LEVELS, TIME OF OPERATIONS, MIXING ACROSS SUBGROUPS, AND AVOIDINGDUPLICATIONOF RESPONDENTS) 
1. Can you tell me what you do on a typical weekday during the day? And during the evening?

2. Can you tell me what you do on a typical Saturday or Sunday day time? And in the evenings? FREE LIST ALL THE ACTIVITIES AND WAIT FOR CUES FROM THEIR RESPONSESWHICHCOULDBEAGOOD LINKAGETOMSMACTIVITIES.

3. Where do MSM principally live/ stay? With whom? Are there any special patterns of residence?

PROBE FOR ORDINARY RESSIDENCE, BROTHELS, STREET,ETC:

a. What parts of town (MENTION) can we find the street-based MSM? Other types of MSM? PROBE FORTYPESOFMSM. [GET SPECIFICLOCATIONS. OBTAIN/ PRODUCE MAP?]

4. Please think about this next question very carefully and take your time. About how many other people do you personally know who are also MSM? By personally knowing them, Imean you know them by nameand they also know your name.

5. Where do you usually meet these friends? How often do you usually meet/ see them? How do you usually meet them (i.e., transport? Do you have to travel far or are you all in the sameareas)?

6a Where do MSM typically meet to socialize or hook up? Is there connection between MSM and IDUs? Do you know people who inject in galleries? [PROBE WHAT IS THE RELATIONSHIP BETWEEN PEOPLE WHO MEET IN DIFFERENT PLACES? ARE THESE DIFFERENT GROUPS NETWORKED AMONGST THEMSELVES AS WELLAS ACROSSGROUPS?]

6b. How many people do you know, and they know you, you know their name and they know yours, who are also MSM (HAVE HAD SEX WITH ANOTHER MAN INTHE PAST ONE YEAR), who used to live or work here but moved out [PROBE FOR] one month ago, three months ago, six months ago?

[SAY TO THE RESPONDENT:] Let me tell you a little more about the study that will be starting in a few months. We are inviting people who have sex with men to participate in a study. This would require you to come to a study site and a professional interviewer will conduct a one-on-one interview with you. The interviewer will ask you questions about HIV knowledge, and your sexual and other practices. It would take about an hour and a half for the whole study. We are not going to collect any names and interviews will be held in a private room one-on-one with an interviewer. There will also be HIV testing (which will be completely private) as part of the study. 
3. Doyou think people would be willing to participate in this study?

4. What would prevent people from coming to the study?

5. Whatkind of MSMmay not want to do this study?

6. We want to make sure that the place where we do the study is comfortable and accessible for people. What area of town would be easiest for MSM to get to? Are there parts of town that MSMwould not feel comfortable going to?

7. After the study, we would ask participants to recruit other people who are also MSM. These must be friends; they cannot be strangers. You would get a small reimbursement for successfully recruiting your friends. How likely do you think you would recruit others? How many people do you think you can actually recruit into the study?

8. What would prevent people from recruiting friends who are MSM?

9. What are the best days of the week and best times of the day to do the data collection so that it will be most convenient for people?

10. Would MSM be interested in attending health services for men (i.e., a male friendly clinic that offers services to high-risk men including HIV and STI testing)?

11. Sometimes people pretend to be MSM so that they can also participate in the study. How can I tell if someone is really MSM or not? Are there questions that I might be able to ask to see is she/ he is really MSM or not? Maybe there are some things that someone who does not have sex with men would not know? Can you think of anythinglike that?

\section{Materials}

EXPLAIN PURPOSE OF THIS SECTION BY SAYING: You will be given coupons which you will use to recruit other MSM.

16. Do you havea preference of what color these coupons should be? These coupons a $\mathrm{r} \mathrm{e}$ about the size of , do you think they should be smaller or larger?

17. What kinds of information do you think we should put on the coupons?

18. Do you think a map on the coupon will be helpful for finding the interview site? PROBEFORREASONS.

19. We would like to offer educational materials/ supplies to MSM who participate in the study. What health topics are of mostinterest to MSM?

20. Do you think MSMwill review written materials on these subjects?

21. Do you think MSMbe interested in receiving free condoms?

22. Is there anything else about which MSMwould want to receive information? 


\section{Acceptability of IBBSS-RDS}

\section{DESCRIBE YOUR RDSSTUDY PROCEDURES, THENASK:}

23. How likely do you think MSM would be to join a project like this? What sounds most interesting about this project? What sounds least interesting about this project?

24. How likely do you think it is that you could recruit your friends?

25. How many coupons out of three do you think you can give to your friends and your friends would actually show up?

26. What do you think would prevent your friends from coming to see us?

27. If part of the survey includes taking an HIV test, how likely do you think it is that your friends would join? What aboutyou?

28. What if we also ask you and your friends to screen for other STIs?

\section{Clinic services}

29. Do you think MSM are at higher risk for STI's? Do most MSM know they are at higher risk? Would they beinterested in receiving additional services outside HIV testing?

30. Are certain types of MSMmore at risk for STIs/ HIV? PROBE.

31. Do you know where you can go to get a confidential HIV test and results? STI exam and results?

32. Have you ever had an HIV test/ STI exam? If so, where? Did you get your results? Did you get treatment? How did thestaff treatyou? Did the staff know you were a MSM?

33. Would you be willing to go to [NAME SITE] if we gave you a voucher for a free HIV test/ STI exam? Why or why not?

THANK PARTICIPANT FOR TIME AND INVITETHEMTO MAKEANY COMMENTSONTHE INTERVIEW OR SURVEY AND OFFER TO ADDRESS THEM TO THE BEST OF YOUR ABILITY.NOTETIMEOF CLOSE. 


\section{Formative IBBSSAssessment with MSM}

\section{Key Informant Interview Guide}

\section{(For Use with Community Leaders, Outreach Persons)}

We would like to start our recruitment with some MSM who are highly networked and influential within their own communities. Can you think of any MSM who would make good participants for our survey? (i.e., who know a lot of other MSM, speak well, are well-liked by their peers, and would beinterested in our study goals)?

\section{Geographic understanding}

1. Is there an active MSM/ IDU population in this city? Do the MSM/ IDUs have an association?PROBEFORMEMBERSHIP.

2. Can you describe the areas where MSM pick up clients? Can you describe the areas where IDUs inject, buy drugs, or spend time? (MAY WANT TO SPECIFY: DIRECT ESTABLISHMENTS, BARS/ KARAOKE/ RESTAURANTS, PARKS OR OTHER STREET LOCATIONS)

3. If we wanted to find MSM for the study we are planning, what would be the best way to locate them? (e.g. through clinic staff, direct identification at injecting locations, through NGOs?) PROBEFORFINDINGSEEDS.

4. [FOROUTREACH INFORMANTS] When you do outreach to MSM, what contact do you have with establishment owners or other authorities? The police? Have you had difficulties with getting access to MSMbecause of any of these kinds of authorities?

5. [FOR OUTREACH INFORMANTS] Can you describe the areas where you and your team do outreach to MSM? (MAY WANT TO SPECIFY: DIRECT ESTABLISHMENTS, BARS/ KARAOKE/ RESTAURANTS, PARKSOROTHER STREET LOCATIONS.

[ALLKEY INFORMANTS) Are there other places in this area where MSM hang out?

\section{IBBSSLogistics}

6. About how much would you expect their transport to the interview site to cost? (BASE INCENTIVE LEVELONCOST FORTRANSPORTATION).

7. Do you think that [INSERT NAIRA AMOUNT] is sufficient to encourage MSM to participate in our study (our study includes an interview and a biological specimen, and could take up to one hour to complete)?

8. [IFYOUDONOT HAVEANINTERVIEW SITE SELECTED, THENASK]: 
- Where do you think would be a location for an accessible, comfortable place for MSM to go to participatein a study?

- How many sites do you think are necessary for a city/ town of this size? If more than one site is suggested, where do you think these sites should be located?

- What are the characteristics of an interview site (somewhere will you will be interviewed and have blood taken) that would make it most comfortable?

THANK PARTICIPANT FOR TIMEAND INVITE THEMTO MAKE ANY COMMENTSONTHE INTERVIEW OR SURVEY AND OFFER TO ADDRESS THEM TO THE BEST OF YOUR ABILITY.NOTETIMEOFCLOSE.

\section{Formative IBBSSAssessment with MSM}

\section{Focus Group Discussion}

DESCRIBE PURPOSE OF STUDY, HIGHLIGHTING ITS LINKAGE WITH THE 2009 IBBSS, AND SOLICITING COOPERATION FOR BOTH ACTIVITIES. ASSURE OF CONFIDENTIALITY, ADMINISTER CONSENT, AND CREATE COMFORTABLE ATMOSPHERE. DESCRIBE ORGANIZATIONOF DISCUSSION AROUND CORE ISSUES AND THAT THE ENTIREDISCUSSIONSHOULD LAST LESSTHAN2 HRS.

THIS GUIDE WILL BE USED TO EXPLORE OPERATIONAL ISSUES RELATED TO DATA COLLECTION USING RDS (I.E., WILLINGNESS TO RECRUIT, SIZE OF PERSONAL NETWORKS, INCENTIVE LEVELS, TIME OF OPERATIONS, MIXING ACROSS SUBGROUPS, AND AVOIDING DUPLICATIONOF RESPONDENTS)

1. [FUNNEL THE QUESTIONS - I.E. FLAG OFF WITH GENERAL QUESTIONS, LEADING TO THE SPECIFIC ONES YOU WILL ASK BELOW, TO MAINTAIN RAPPORT AND NOT TO CREATE DISCOMFORT AMONGPARTICIPANTS- THENASK]Can you tell me what MSMdo on a typical weekday during the day? And during the evening?

2. Can you tell me what MSM do on a typical Saturday or Sunday day time? And in the evenings? FREE LIST ALL ACTIVITIES, WAIT FOR CUES FROMTHEIR RESPONSES WHICHCOULD BEAGOOD LINKAGETO MSMACTIVITIES. PROBE.

3. Where do MSM principally live/ stay? With whom? Are there any special patterns of residence?

\section{PROBEFORORDINARY RESSIDENCE, BROTHELS, STREET, ETC:}

a. What parts of town (MENTION) can we find the street-based MSM? Other types of MSM? PROBE FOR TYPES OF MSM. [GET SPECIFIC LOCATIONS. OBTAIN/ PRODUCEMAP?]

4. Where do MSMusually meet their friends? How often do they usually meet/ see? How do they usually meet them (i.e., transport? Do they have to travel far or are they all in the sameareas)? PROBE FOR PROXIMITY AND DISTANCE. 
5. Where do MSM typically meet to socialize or hook up? Is there connection between MSM and IDUs? Do you know people who inject in galleries? [PROBE FOR THE RELATIONSHIP BETWEEN PEOPLE WHO MEET IN DIFFERENT PLACES? ARE THESE DIFFERENT GROUPS NETWORKED AMONGST THEMSELVES AS WELL AS ACROSSGROUPS?]

[SAY TO THE GROUP:] Let me tell you a little more about the study that will be starting in a few months. We are inviting people who have sex with men to participate in a study. This would require you to come to a study site and a professional interviewer will conduct a oneon-one interview with you. The interviewer will ask you questions about HIV knowledge, and your sexual and other practices. It would take about an hour and a half for the whole study. We are not going to collect any names and interviews will be held in a private room one-on-one with an interviewer. There will also be HIV testing (which will be completely private) as part of the study.

6. Doyou think people would be willing to participatein this study?

7. What would prevent peoplefrom coming to the study?

8. What kind of MSMmay not want to do this study?

9. We want to make sure that the place where we do the study is comfortable and accessible for people. What area of town would be easiest for MSM like yourselves to get to? Are there certain parts of town that MSMwould not feel comfortable going to?

10. After the study, we would ask participants to recruit other people who are also MSM. These must be friends; they cannot be strangers. You would get a small reimbursement for successfully recruiting your friends. How likely do you think you would recruit others? How many people do you think you can actually recruit into the study?

11. What would prevent peoplefrom recruiting friends who are MSM?

12. What are the best days of the week and best times of the day to do the data collection so that it will be most convenient for people?

13. How willing would people be to participate in another paid study? How willing are people to be screened for STIs (blood, swab etc)? What would the appropriate compensation be? PROBE: Would they be willing to do this within a week of the IBBSS? How far are peo ple willing to travel for these services? Is it feasible to have people go immediately after they participatein the IBBSS? 
14. Sometimes people pretend to be MSM so that they can also participate in the study. How can I tell if someone is really MSMor not? Are there questions that I might be able to ask to see is she/ he is really MSM or not? Maybe there are some things that someone who does not have sex with men would not know? Can you think of anythinglike that?

15. In your view, do MSM move in and out frequently from this area, whether temporarily or permanently? PROBE FOR REASONS, PATTERNS, SEASONALITY OF MOVEMENTS.

16. SAY: To clarify your answers to the questions on movement, could you give me an idea of how many MSM in this area identify themselves as gay men? PROBE FOR THE DIFFERENT WAYS OF DEFINING THEIR SEXUALITY. PROBE FOR DIFFERENT TERMINOLOGIESFOR THEDIFFERENT TYPESOFGAY MEN.

\section{IBBSSMaterials}

EXPLAINPURPOSEOFTHISSECTIONBY SAYING: You will be given coupons which you wil use to recruit other MSM.

18. Do you have a preference of what color these coupons should be? These coupons are about the size of , do you think they should be smaller or larger?

19. Whatkinds of information do you think we should put on the coupons?

20. Do you think a map on the coupon will be helpful for finding the interview site? PROBE FORREASONS.

21. We would like to offer educational materials/ supplies to MSM who participate in the study. What health topics are of mostinterest to MSM?

22. Do you think MSMwill review written materials on these subjects?

23. Do you think MSM be interested in receiving free condoms? Is there anything else about which MSMwould want to receive information?

\section{Acceptability of IBBSS-RDS}

\section{DESCRIBE YOUR RDSSTUDY PROCEDURES, THENASK:}

24. How likely do you think MSM would be to join a project like this? What sounds most interesting about this project? What sounds least interesting about this project?

25. How likely do you think it is that you could recruityour friends?

26. How many coupons out of three do you think you can give to your friends and your 
friends would actually show up?

27. What do you think would prevent your friends from coming to see us?

28. If part of the survey includes taking an HIV test, how likely do you think it is that your friends would join? Whataboutyou?

29. What if wealso ask you and your friends to screen for other STIs?

\section{Clinic services}

30. Do you think MSMare at higher risk for STI's? Do most MSM know they are at higher risk? Would they be interested in receiving additional services outside HIV testing?

31. Are certain types of MSM at more risk for STIs/ HIV than others? PROBE FOR TYPES OF MSMAGAINAND FORDISTRIBUTIONOFRISKAMONGSUB-POPULATIONS.

32. Do you know where MSM can go to get a confidential HIV test and results? STI exam and results?

33. Would MSM be willing to go to [NAME SITE] if we gave them a voucher for a free HIV test/ STI exam? Why or why not?

THANK PARTICIPANTS FOR TIME AND INVITE THEM TO MAKE ANY COMMENTS ON THE INTERVIEW OR SURVEY AND OFFER TO ADDRESS THEM TO THE BEST OF YOUR ABILITY.NOTETIMEOFCLOSE. 


\section{Formative IBBSSAssessment with MSM}

\section{Observation Checklist}

The core professional requirement for use of this instrument by the field staff is explicit awareness of one's environment. The events to be observed are organized around 10 basic dimensions of the current pre-assessment, viz.:

1. Geographic spread.

2. Networking dynamics, including target population size, formation patterns, density and mobility through timeand space.

3. IBBSS logistics, which include selection of interview or referral sites and other operational concerns.

4. Educational materials and supplies that may be needed for the IBBSS

5. Seed selection issues

6. MSMsex practices

7. IDUinjecting practices

8. Clinic services

9. Acceptability of IBBSS-RDS

10. Security

Information on these core issues will not only help operational processes of the 2009 IBBSS but will also produce help contextualize the IBBSS results. For this reason, you should:

1. Observe for places where events occur or relevant activities take place;

2. Note the acts, actions, activities, and actors;

3. Identify the nature of feelings or type of emotions attached to what you are observing by those you are observing;

4. Describetheobjects in use for the interactions;

5. Describe the goals people have for engagingin the observed activity;

6. Identify existing patterns, that transform simple actions into events; and

7. Pay close attention to the time during which the interactions occur. Note variations, transitions, terminations.

\section{Geographical spread}

- Is there an active MSM/ IDU population in this city? How does it operate? How is it spread across the city?

- $\quad$ Can you describe the areas where MSM pick up clients? How are clients spread out across the city? Can you describe the areas where IDUs inject, buy drugs, or spend time?

- What are the hot spots for MSMand IDUactivities? 


\section{Network dynamics (size, mobility and density)}

- In your view, do MSM/ IDUs move in and out frequently from this area, whether temporarily or permanently? How can you tell?

\section{IBBSSLogistics}

- Transport cost to the interview sites for MSM and IDUs? Would that amount be enough to encourage MSM/ IDUs to participate in the IBBSS ( given its interview and biological specimen components)?

- Would MSM/ IDUs feel comfortable coming to selected site for interview? What are the most convenient times of the day for MSM/ IDUs to go to an interview site to participate in a study? Why do think so?

- Which days of the week do you think MSM/ IDUs would be most likely to go to an interview site to participatein a study? Why do you think so?

- Do you think IDUs and MSMwould be willing to be interviewed at the same interview siteif this were the only site? Why do you think so?

\section{Types of sex work for MSM/ injectingpractices for IDUs}

\section{IT MAY NOT BE REALISTIC TO EXPECT THAT YOU WILL OBSERVE THESE WITHINTHE SHORT PERIOD YOU HAVETO SPEND INTHE FIELD, BUT JUST KEEP ANEYEOUT.}

- Describe different types of MSM (brothel, street, karaoke, home based. Do you think the MSM who work at a venue also sometimes work outside the venue like at a street or in a park? Is it common for someone to work in multiple sites?

- $\quad$ Are there foreign (or other subpopulations) MSM living in this area? If so, do they comprise a large group? Do they speak thelocallanguage(s)? comprisealarge group? Do they speak the local language(s)?

- $\quad$ Are there foreign IDUs (or other subpopulations) living in this area? If so, do they comprise a large group? Do they speak the local language(s)?Do you think IDUs move around the city? Why doyou thinkso?

\section{Acceptability of IBBSS-RDS}

- Will MSM/IDUs join a project like this? Why do you think do? PROVIDE REFLECTIONS. 


\section{Technical Committee}

\begin{tabular}{|l|l|l|}
\hline S/N & NAME & ORGANIZATION \\
\hline 1 & Dr. Wapada Balami, mni & HIV/ AIDS Division, FMOH, Abuja \\
\hline 2 & Dr. Aderemi Azeez & HIV/ AIDS Division, FMOH, Abuja \\
\hline 3 & Dr. Issa Kawu & HIV/ AIDS Division, FMOH, Abuja \\
\hline 4 & Dr. Adebobola Bashorun & HIV/ AIDS Division, FMOH, Abuja \\
\hline 5 & Mr. Alex Onwuchekwa & HIV/ AIDS Division, FMOH, Abuja \\
\hline 6 & Ms. Perpetua Amodu & HIV/ AIDS Division, FMOH, Abuja \\
\hline 7 & Dr. Peter Nwokennaya & HIV/ AIDS Division, FMOH, Abuja \\
\hline 8 & Mr. Gabriel Ikwulono & HIV/ AIDS Division, FMOH, Abuja \\
\hline 9 & Mrs. Odekunle & HIV/ AIDS Division, FMOH, Abuja \\
\hline 10 & Mr. Kassim Amodu & HIV/ AIDS Division, FMOH, Abuja \\
\hline 11 & Dr. Sade Adebanjo & Lagos State AIDS Control Agency (LSACA) \\
\hline 12 & Dr. Omokhudu Idigho & Enhancing Nigeria's Response to \\
& & HIV and AIDS (ENR) \\
\hline 13 & Dr. Sylvia Adebajo & ENR/ Population Council \\
\hline 14 & Mr. Apera Iorwakwagh & ENR/ Population Council \\
\hline 15 & Ms. Lolade Abiodun & ENR/ Population Council \\
\hline 16 & Dr. Emeka Nwachukwu & ENR/ Population Council \\
\hline 17 & Olusegun Sangowawa & ENR/ Population Council \\
\hline 18 & Waimar Tun & ENR/ Population Council \\
\hline 19 & Meredith Sheehy & ENR/ Population Council \\
\hline 20 & Andrew Karlyn & ENR Population Council \\
\hline 21 & Mr. Onoriode Ezire & ENR/ SFH \\
\hline 22 & Dr. Zana Zonda & ENR \\
\hline 23 & Dr. Samson Adebayo & Society for Family Health (SFH) \\
\hline 24 & Dr. Jennifer Anyanti & Society for Family Health \\
\hline 25 & Mr. Richard Fakolade & \\
\hline
\end{tabular}




\begin{tabular}{|c|c|c|}
\hline 26 & Mallam Usman Yusuf & Independent Consultant \\
\hline 27 & Mr. Oliver Anene & Male Attitude Network, Abuja \\
\hline 28 & Mr. Dennis Akpona & $\begin{array}{l}\text { The Independent Project for Equal } \\
\text { Rights, Lagos }\end{array}$ \\
\hline 29 & Mr. Kayode Fasusi & $\begin{array}{l}\text { The Independent Project for Equal } \\
\text { Rights, Ibadan }\end{array}$ \\
\hline 30 & Mr. Cheidu Ifankendu & Green Trust Network, Kaduna \\
\hline 31 & Dr. Bolatito Aiyenigba & FHI/ GHAIN \\
\hline 32 & Dr. Abdul Yusuf & FHI/ GHAIN \\
\hline 33 & Dr. George Eluwa & FHI/ GHAIN \\
\hline 34 & Ms. Titilope Badru & FHI/ GHAIN \\
\hline 35 & Dr. Oka Obono & Consultant, University of Ibadan \\
\hline 36 & Dr. Kayode Osungbade & Dept of Comm. Medicine, UCH, Ibadan \\
\hline 37 & Dr. Taofeek Ibrahim & $\begin{array}{l}\text { Dept of Comm. Medicine, Uthman Dan Fodio } \\
\text { University, Sokoto }\end{array}$ \\
\hline 38 & Dr. Tunde Adedokun & Dept of Medical Bio-Statistics, UCH, Ibadan \\
\hline
\end{tabular}


